\title{
Krankheiten, Sterben und Tod Kaiser Rudolfs II. in Prag
}

\author{
Von Václav Bůžek und Pavel Marek
}

\begin{abstract}
Maladies, dying and the death of Emperor Rudolf II in Prague
According to the testimony of the personal doctors of Rudolf II, the fatally ill emperor remained fully conscious until his death in Prague Castle on 20 January 1612 between six and seven o'clock in the morning. The contents of the autopsy report suggest that neither an advanced infectious, probably syphilitic disease, nor tuberculosis, as was claimed both in older and more recent specialized literature, could have been the only cause of Rudolf II's death. While the health of the emperor was also affected by respiratory and digestive diseases, his death may have been accelerated by heart disease. After the autopsy, embalmment and dressing of Rudolf II's dead body, it was publicly exposed in the audience hall on the second floor of Prague Castle South Wing on 21 January. During the night before 6 February the corpse was carried through the Vladislav Hall to the All Saints' Church in Prague Castle where it was temporarily shown in an open coffin. The celebrations of the immortality of the deceased emperor's social body culminated in Catholic funeral services in Antwerp, Brussels, Florence, Madrid, Prague and cities of the Holy Roman Empire. Each of these last farewells to Rudolf II differed in timing, expense, attendance of funeral guests and dramaturgy of symbolical ceremonies. From the display of his corpse until the requiems, Rudolf II entered the collective memory of contemporaries as a virtuous monarch, Christian knight and a fighter for the Catholic confession, who by the grace of God took over the sovereign efforts of his famous ancestors from the Habsburg dynasty.

Keywords: Rudolf II of Habsburg; illnesses; death; autopsy; causes of death; dead corpse display; funeral ceremony; celebration of immortal social body

Schlagworte: Rudolf II. von Habsburg; Krankheiten; Tod; Autopsie; Todesursachen; Aufbahrung des Leichnams; Begräbniszeremonien; Glorifizierung des sozialen Körpers
\end{abstract}

Während der letzten zehn Jahre seines Lebens verbreiteten sich aus der Residenz Kaiser Rudolfs II. auf der Prager Burg widersprüchliche Bilder des mitteleuropäischen Herrschers aus der habsburgischen Dynastie ${ }^{1}$, der nach dem Tod seines Vaters Maximilian II.

${ }^{1}$ Anton Gindely, Rudolf II. und seine Zeit. 1600-1612, 2 Bde. (Praha 1863-1865); Jan Bedřich Novák, Rudolf II. a jeho pád [Rudolf II. und sein Sturz] (Praha 1935); Robert John Weston Evans, Rudolf II and His World. A Study in Intellectual History 1576-1612 (Oxford 1973); tschechische Übersetzung Robert John W. Evans, Rudolf II. a jeho svět. Myšlení a kultura ve střední Evropě 1576-1612 [Rudolf II. und seine Welt. Denken und Kultur im Mitteleuropa 1576-1612] (Praha 1997); Karl VoCELKA, Rudolf II. und seine Zeit (Wien-Köln-Graz 1985); Josef JANÁČEK, Rudolf II. a jeho doba [Rudolf II. und seine Zeit] (Praha 1987); Prag um 1600. Beiträge zur Kunst und Kultur am Hofe Rudolfs II. (Essen-Freren 1988); Eliška Fučíková-Beket Bukovinská-Ivan MuchKa, Umění na dvoře Rudolfa II. [Die Kunst am Hofe Rudolfs II.] (Praha 1991); Eliška Fučíková et al., Rudolf II. a Praha. Císařský dvůr a rezidenční město jako kulturní a duchovní centrum střední Evropy [Rudolf II. und Prag. Der Kaiserhof 
seit 1576 das Römisch-Deutsche Reich und die böhmischen wie ungarischen Länder regierte $^{2}$. Die offizielle Propaganda stellte den römischen Kaiser, den böhmischen und ungarischen König als christlichen Ritter dar, der mit der Waffe in der Hand den Glauben Jesu Christi und die katholische Religion gegen die Angriffe der Andersgläubigen auf dem ungarischen Schlachtfeld verteidigte, obwohl er persönlich nie an der Spitze seiner Armee in den Feldzügen gegen die Osmanen stand ${ }^{3}$. Ein ganz anderes Bild des Monarchen vermittelten die Berichte der ausländischen Gesandten vom Kaiserhof, der Reisenden und der Besucher in Prag. In ihren Zeugnissen trat Rudolf II. als ein Eigenbrötler ohne jegliches Interesse an staatlichen Angelegenheiten auf, der sich jedoch für die Kunst der Spätrenaissance und des Manierismus, die Naturwissenschaften, die Alchemie, die jüdische Mystik, den Okkultismus und die Jagd leidenschaftlich zu begeistern wusste ${ }^{4}$. Das Bild eines psychisch unausgewogenen Herrschers rundeten die Meldungen über seinen sich zunehmend verschlechternden Gesundheitszustand und sein ungeordnetes Privatleben ab ${ }^{5}$. Den Beobachtern blieb nicht verborgen, dass Rudolf II. sich hartnäckig weigerte, eine Ehe einzugehen und legitime Nachkommen zu zeugen. Die widersprüchliche Wahrnehmung des Kaisers vervollständigten zu Beginn des 17. Jahrhunderts die Berichte über seine sexuellen Vorlieben ${ }^{6}$.

und die Residenzstadt als kulturelles und geistliches Zentrum Mitteleuropas] (Praha-London-Milano 1997); Jaroslava Hausenblasová-Michal ŠroněK, Urbs aurea. Praha císaře Rudolfa II. [Urbs aurea. Prag des Kaisers Rudolf II.] (Praha 1997); Alchymie a Rudolf II. Hledání tajemství př́rody ve střední Evropě v 16. a 17. století [Alchemie und Rudolf II. Das Suchen des Naturgeheimnisses in Mitteleuropa im 16. und 17. Jahrhundert], hg. von Ivo Purš-Vladimír Karpenko (Praha 2011). - Folgende Abkürzungen wurden verwendet: ASMa = Archivio di Stato di Mantova; HHStA, FA = Haus-, Hof- und Staatsarchiv, Wien, Familienakten; NA, SO, CA = Národní archiv Praha [Nationalarchiv Prag], Sbírka opisů [Sammlung der Abschriften], Cizí archivy [Fremde Archive - Orte der Archive]; SOA Třeboň = Státní oblastní archiv v Třeboni [Staatliches Regionalarchiv Wittingau].

2 Obwohl Rudolf II. die Würde des österreichischen Erzherzogs innehatte, regierte er nicht unmittelbar über die österreichischen Erblande. Ober- und Niederösterreich verwalteten nach dem Tod ihres Vaters Brüder Rudolfs II. Zuerst wurde Erzherzog Ernst zum Landesherrn. Nach dessen Abgang nach Brüssel verlieh er Erzherzog Matthias im Jahre 1593 die Obergewalt über die beiden Länder. Über Tirol und Vorderösterreich regierte bis 1595 Rudolfs Onkel Ferdinand von Tirol. Nach den langwierigen Auseinandersetzungen um das Erbe wurde Erzherzog Maximilian, der Bruder Rudolfs II., zum Landesherrn von Tirol und Vorderösterreich. Als im Jahre 1590 Rudolfs Onkel Erzherzog Karl gestorben war, wurde in Innerösterreich vorübergehend eine Regentenregierung ernannt. Erst 1596 übernahm die Obergewalt über Innerösterreich Rudolfs Cousin Erzherzog Ferdinand von der Steiermark. Vgl. Thomas WINKeLBAUER, Ständefreiheit und Fürstenmacht. Länder und Untertanen des Hauses Habsburg im konfessionellen Zeitalter I (Österreichische Geschichte 1522-1699, hg. von Herwig Wolfram, Wien 2003) 4447.

${ }^{3}$ Karl VocelKa, Die politische Propaganda Kaiser Rudolfs II. (1576-1612) (Veröffentlichungen der Kommission für die Geschichte Österreichs 9, Wien 1981) 219-299.

${ }^{4}$ Cesare Campori (Bearb.), Roderico Alidosi, Relazione di Germania e della corte di Rodolfo II. Imperatore negli anni 1605-1607 fatta da Roderici Alidosi ambasciatore del Granduca di Toscana Ferdinando I. (Modena 1872) 5-7; Fynes Moryson-John Taylor, Cesta do Čech [Fynes Moryson-John Taylor, Die Reise nach Böhmen], hg. von Alois Bejвlík (Praha 1977) 79f.; Tři francouzští kavalíri v rudolfínské Praze. Jacques Esprinchard, Pierre Bergeron, François de Bassompierre, hg. von Eliška Fučíková [Drei französische Kavaliere im Rudolphinischen Prag. Jacques Esprinchard, Pierre Bergeron, François de Bassompierre] (Praha 1989) 44-59; Albert BABEAU, Une ambassade en Allemagne sous Henri IV. Revue Historique 21 (1896) 28-49.

5 Tři francouzští kavalíri (wie Anm. 4) 47, 51.

6 Campori (Bearb.), Roderico Alidosi, Relazione di Germania (wie Anm. 4) 5-7; Fynes MorysonJohn Taylor, Cesta do Cech (wie Anm. 4) $79 f$. 
Die historische Forschung hat verschiedentlich dargelegt, dass das zeitgenössische Bild Rudolfs II. zahlreiche Risse aufweist. Obwohl politische Entschlossenheit sicherlich nicht die stärkste Seite seiner Persönlichkeit war, drückte sich Rudolf umgekehrt nicht vor seinen Pflichten und kam auf der Prager Burg, die seit 1583 seine dauerhafte Residenz war, seinen staatlichen Pflichten nach ${ }^{7}$. Obwohl er von seiner kaiserlichen Würde überzeugt war, wagte es Rudolf II. dennoch nicht, gegen die Interessen seiner spanischen Verwandten aufzutreten, sei es beim Streit um die norditalienische Grafschaft Finale, sei es bei seiner geplanten Eheverbindung mit Isabella Clara Eugenia von Spanien ${ }^{8}$. Angesichts der angespannten religiösen und politischen Situation im Heiligen Römischen Reich und in den einzelnen Ländern der Habsburgermonarchie ließ er es nie bis zum Äußersten kommen und wählte stets einen Weg der Kompromisse, durch die er auch seine Herrschermacht festigen wollte. Dies verdeutlicht die wenig zielgerichtete Suche nach einer Lösung in der Konfrontation zwischen Protestanten und Katholiken, für welche im letzten Viertel des 16. Jahrhunderts die Mechanismen des mühsam ausgehandelten Augsburger Religionsfriedens allmählich versagten?

Die Wahl eines Mittelwegs war lange Zeit auch für Rudolfs Herrschaftskonzeption im Königreich Böhmen, das die wichtigste Stütze seiner politischen und finanziellen Macht darstellte, bestimmend. Dort setzte der Kaiser konsequent die Rekatholisierung durch, doch bemühte er sich gleichzeitig darum, Katholiken und Nichtkatholiken einen Anteil in der Landesverwaltung zukommen zu lassen, da er einen offenen Ausbruch der latenten Spannung vermeiden wollte. Neben katholischen Hofleuten schenkte Rudolf II. auch lutherischen und calvinistischen Hofleuten, aber auch Vertretern der verbotenen Brüderunität Vertrauen ${ }^{10}$. Trotz seines langjährigen Aufenthalts am spanischen Königshof, wo er sich, so wie es sich seine Mutter gewünscht hatte, die Grundlagen des nachtridentinischen Katholizismus aneignete, näherte er sich politisch den moderaten Lösungen Maximilians II. an ${ }^{11}$. Dem entsprach auch seine pragmatische Haltung gegenüber den Plänen des Heiligen Stuhls ${ }^{12}$. Zum Opfer seiner politischen und religiösen

7 Jaroslav PÁNEK, K povaze vlády Rudolfa II. v Českém království [Zur Frage der Regierungsstrategie Rudolfs II. im Königreich Böhmen]. Folia historica bohemica 18 (1997) 71-86; Der Hof Kaiser Rudolfs II. Eine Edition der Hofstaatsverzeichnisse 1576-1612, hg. von Jaroslava Hausenblasová (Fontes historiae artium 9, Praha 2002); Documenta Polonica ex Archivo Generali Hispaniae in Simancas. Nova Series I, hg. von Ryszard Skowron et alii (Kraków 2015).

8 Pavel MareK, La embajada española en la corte imperial 1558-1641. Figuras de los embajadores y estrategias clientelares (Praha 2013) 62-82.

9 Volker Press, Rudolf II. 1576-1612, in: Die Kaiser der Neuzeit 1519-1918. Heiliges Römisches Reich, Österreich, Deutschland, hg. von Anton Schindling-Walter Ziegler (München 1990) 99-111, 475-477, hier 107-109.

${ }^{10}$ Mit den Belegen Václav BƯŽEK, Konfessionelle Pluralität in der kaiserlichen Leibkammer zu Beginn des 17. Jahrhunderts, in: Konfessionelle Pluralität als Herausforderung. Koexistenz und Konflikt in Spätmittelalter und Früher Neuzeit. Winfried Eberhard zum 65. Geburtstag, hg. von Joachim BaHLCKe-Karen Lambrecht-Hans-Christian Maner (Leipzig 2006) 381-395; Ders., Heinrich Julius von Braunschweig-Wolfenbüttel am Prager Kaiserhof, in: Herzog Heinrich Julius zu Braunschweig und Lüneburg (1564-1613): Politiker und Gelehrter mit europäischem Profil, hg. von Werner ArNoLD-Brage Bei Der Wieden-Ulrike Gleixner (Quellen und Forschungen zur braunschweigischen Geschichte 49, Braunschweig 2016) 42-56.

11 Näher PÁneK, K povaze vlády (wie Anm. 7) 81-84.

12 Tomáš ČernušÁk, Nunciatura u císařského dvora v prvních letech vlády Rudolfa II. a české země [Die Nuntiatur am Kaiserhof in den ersten Jahren der Regierung Rudolfs II. und die böhmischen Länder]. Český časopis historický 111 (2013) 728-742, hier 735. 
Kompromisse, zu denen auch der Erlass des Majestätsbriefes bezüglich der Glaubensfreiheit gehörte, wurde er in der Auseinandersetzung mit Erzherzog Matthias in den Jahren 1608 bis $1611^{13}$. Das Ergebnis des Bruderkonflikts brachte Rudolf II. nicht nur den Verlust Mährens und Ungarns, sondern führte auch die vollständige Schwächung seiner königlichen Macht in Böhmen herbei. Der schwerkranke Kaiser wollte sie mit der politisch unklugen Berufung der Passauer Truppen retten ${ }^{14}$.

Dem Gesundheitszustand Rudolfs II. wandten die Historiker in der Regel ihre Aufmerksamkeit dann zu, wenn sie Antworten auf Fragen suchten, die nicht nur das komplizierte Privatleben des Herrschers betrafen, sondern die auch mit seinem scheinbar geringen Interesse an der Erfüllung seiner Herrscherpflichten, an der Nachfolge auf dem Kaiserthron und mit seinem Versagen als Staatsmann am Ende seines Lebens zusammenhängen ${ }^{15}$. Zuerst sahen die Forscher die Ursachen der psychischen Unausgeglichenheit Rudolfs II. in einer Erkrankung neurologischer Art, die sie sich durch die genetischen Voraussetzungen der Familienanamnese der Habsburger erklärten ${ }^{16}$. Später brachten einige Forscher die unnatürliche Gereizheit und den Jähzorns des Herrschers vor allem mit der Syphilis, an der Rudolf vermutlich seit seinem dreißigsten Lebensjahr litt, in Zusammenhang ${ }^{17}$. Den neueren Biographen Rudolfs II. blieb nicht verborgen, dass der Kaiser darüber hinaus langfristig vor allem auch an Funktionsstörungen der Lunge und der Leber litt ${ }^{18}$. In jüngster Zeit wurde auch die Vermutung geäußert, dass die Erkrankung Rudolfs II. Symptome der Tuberkulose aufwies, an der nach langem Leiden auch sein Großvater Ferdinand I. und sein Vater Maximilian II. verstorben waren $^{19}$.

Die Hauptquellen zu Krankheit, Sterben und Tod Rudolfs II. stellen die Arztberichte, die habsburgische Familienkorrespondenz und vor allem die Zeugnisse der auslän-

13 Zuletzt Ein Bruderzwist im Hause Habsburg (1608-1611), hg. von Václav BưžEK (Opera historica 14, České Budějovice 2010); Religion und Politik im frühneuzeitlichen Böhmen. Der Majestätsbrief Kaiser Rudolfs II. von 1609, hg. von Jaroslava Hausenblasová-Jiř́ Mikulec-Martina THOMSEN (Forschungen zur Geschichte und Kultur des östlichen Mitteleuropa 46, Stuttgart 2014).

14 PÁneK, K povaze vlády (wie Anm. 7) 83.

15 Felix STIEve, Die Verhandlungen über die Nachfolge Kaiser Rudolfs II. in den Jahren 15811602. Abhandlungen der historischen Klasse der königlichen bayerischen Akademie der Wissenschaften 15 (1880) 1-159; Karel STLOuKal, Portrét Rudolfa II. z roku 1600 [Das Porträt Rudolfs II. aus dem Jahr 1600], in: Od pravěku k dnešku. Pekařův sborník 2 [Seit der Urzeit bis zur Gegenwart. Pekařs Sammelband II] (Praha 1930) 1-14; Josef MatoušEK, K problému osobnosti Rudolfa II. Poznámky o pramenech, literatuře a metodě [Zum Problem der Persönlichkeit Rudolfs II. Notizen über Quellen, Literatur und Methode], in: K dějinám československým v období humanismu. Sborník prací věnovaných Dru Janu Bedřichu NovÁKovi k 60. narozeninám [Zur tschechoslowakischen Geschichte in der Zeit des Humanismus. Der Sammelband für Dr. Jan Bedřich Novák zum 60. Geburtstag] (Praha 1932) 343362.

16 NovÁk, Rudolf II. a jeho pád (wie Anm. 1) 21-24.

17 Ivan Lesný, Rudolf II. jako nemocný člověk [Rudolf II. als der kranke Mensch]. Folia historica bohemica 7 (1984) 271-280; JANÁČEK, Rudolf II. a jeho doba (wie Anm. 1) 500-502. Hingegen lehnte Evans, Rudolf II. a jeho svět (wie Anm. 1) 69f., die These von der Ansteckung des Kaisers mit der Syphilis ab.

18 JANÁČEK, Rudolf II. a jeho doba (wie Anm. 1) 502.

19 Dazu Paula Sutter Fichtner, A community of illness: Ferdinand I and his family, in: Kaiser Ferdinand I. Aspekte eines Herrscherlebens, hg. von Martina Fuchs-Alfred KoHLER (Geschichte in der Epoche Karls V. 2, Münster 2003) 203-216, hier 215. 
dischen Gesandten, der hohen Hofamtsträger und der Landesbeamten dar ${ }^{20}$. Diese Berichte dienten den modernen Autoren nicht nur zu einer retrospektiven Diagnose von Rudolfs Krankheiten aus der Sicht der modernen Medizin ${ }^{21}$; die Aussagen über den Gesundheitszustand Rudolfs II. ermöglichen, die komplexe und ausgefeilte Gesandtschaftskommunikation in Süd-, West- und Mitteleuropa aufzuzeigen, durch welche das Bild eines kranken Kaisers, der nicht imstande war, seinen Pflichten nachzukommen, vermittelt wurde. Nach seinem Tod stellten diese Texte das Bild vom sozialen Körper Rudolfs II. in den Mittelpunkt und dienten der Verherrlichung seines Nachlebens ${ }^{22}$.

Die ausländischen Gesandten am Kaiserhof begannen Ende der 1570er Jahre dem Gesundheitszustand Rudolfs II. vermehrt Aufmerksamkeit zu schenken ${ }^{23}$. Der päpstliche Nuntius Giovanni Delfino teilte dem Staatssekretär des Apostolischen Stuhls Kardinal Tolomeo Gallio in den Sommer- und Herbstmonaten des Jahres 1577 aus Wien mit, dass der Herrscher sehr schwach sei. Er wies nicht nur auf den langandauernden Husten Rudolfs II. hin, sondern den Nuntius beunruhigten auch dessen wiederholte Magenschmerzen. Einen Eindruck vom sich verschlechternden Gesundheitszustand des Kaisers verschaffte sich Giovanni Delfino während persönlicher Unterredungen und ergänzte seinen Befund mit den dürftigen Aussagen der Leibärzte Rudolfs. Hinter dem Husten, dem Schnupfen und den weiteren Symptomen einer Erkältung sah er Rudolfs Vorliebe für das Trinken kalter Getränke mit Eiswürfeln während der heißen Sommertage ${ }^{24}$. Die Ursachen der lang andauernden Magenschmerzen konnte er sich aber nicht erklären ${ }^{25}$. Die Nachrichten vom Morgenerbrechen des damals fünfundzwanzigjährigen Rudolfs II. ergänzten die Bemerkungen des Nuntius über den Durchfall des Monarchen, in dem die Ärzte größere Reste nicht verdauter Speisen fanden ${ }^{26}$. Giovanni

${ }^{20}$ Anhand der Interpretation der angeführten Quellen veröffentlichten neue Erkenntnisse zu diesem Thema Václav BůžEK-Pavel Marek, Nemoci, smrt a pohřby Rudolfa II. [Die Krankheiten, der Tod und die Begräbnisse Rudolfs II.]. Ceský časopis historický 111 (2013) 1-30; DIES., Smrt Rudolfa II. [Der Tod Rudolfs II.] (Praha 2015).

${ }^{21}$ Wofgang Uwe EcKarT-Robert JüTte, Medizingeschichte. Eine Einführung (Köln-WeimarWien 2007) 325-333.

22 Besonders Barbara Stollberg-Rilinger, Was heißt Kulturgeschichte des Politischen? Eine Einleitung, in: Was heißt Kulturgeschichte des Politischen?, hg. von Ders. (ZHF Beih. 35, Berlin 2005) 924; DIEs., Einleitung, in: Des Kaisers alte Kleider. Verfassungsgeschichte und Symbolsprache des Alten Reiches, hg. von DERs. (München 2008) 7-22; Ernst Hartwig Kantorowicz, The King's Two Bodies: A Study in Medieval Political Theology (Princeton 1957). Der Inhalt der Kommunikation zwischen dem Lebensende, dem Tod und der Verewigung des verstorbenen Kaisers Rudolf II. blieb bisher in der historischen Forschung wenig beachtet. Vgl. Vocelka, Die politische Propaganda (wie Anm. 3) 320-324; JANÁČEK, Rudolf II. a jeho doba (wie Anm. 1) 500-506; Jaroslav PÁNEK, Když císař odchází. Lidská tragédie a posmrtná sláva Rudolfa II. očima současníků [Wenn der Kaiser abgeht. Die menschliche Tragödie und Totenruhm Rudolfs II. in den Augen der Zeitgenossen] (Praha 1997).

${ }_{23}$ Giovanni Delfino an Tolomeo Gallio, Prag, 2.2.1577 - Alexander Koller (Bearb.), Nuntiaturberichte aus Deutschland nebst ergänzenden Aktenstücken. Dritte Abteilung 1572-1585. 9. Band. Nuntiaturen des Giovanni Delfino und des Bartolomeo Portia (1577-1578) (Tübingen 2003) Nr. 11, S. 37-43, hier 42 .

${ }^{24}$ Giovanni Delfino an Tolomeo Gallio, Wien, 17.8.1577 - Koller (Bearb.), Nuntiaturberichte (wie Anm. 23) Nr. 78, S. 212-217, hier 215.

25 Vgl. JANÁČEK, Rudolf II. a jeho doba (wie Anm. 1) 186.

${ }^{26}$ Giovanni Delfino an Tolomeo Gallio, Wien, 31.8.1577 - Koller (Bearb.), Nuntiaturberichte (wie Anm. 23) Nr. 84, S. 224-227, hier 224f.; Giovanni Delfino an Tolomeo Gallio, Wien, 30.11.1577 - Koller (Bearb.), Nuntiaturberichte (wie Anm. 23) Nr. 119, S. 301-304, hier 303. 
Delfino entging zudem nicht, dass Ende des Jahres 1577 nach dem Durchfall eine Verstopfung folgte, sodass die Ärzte Purgiermittel empfahlen ${ }^{27}$.

Den Grad der Erkrankung schätzte der päpstliche Nuntius danach ein, ob der Kaiser seinen Pflichten regelmäßig nachkommen konnte. Er fand es bedenklich, dass Rudolf II. seine Mahlzeiten am liebsten allein einnahm ${ }^{28}$. Ein Grund dafür könnte der schlechte Zustand seines Gebisses gewesen sein, der es Rudolf nicht gestattete, die einzelnen Bissen gut zu zerkauen. Der Nuntius erwähnte dagegen positiv, dass der Kaiser trotz seines schlechten Gesundheitszustandes regelmäßig an den öffentlichen Gottesdiensten in der Hofkapelle teilnahm und beispielsweise ohne Kopfbedeckung an der Spitze einer Prozession einherschritt ${ }^{29}$. Giovanni Delfino bestätigte Ende der 1570er Jahre damit das erwartete Bild Rudolfs II. als frommen Christen, der dank seines festen Glaubens die Gebrechen und Leiden seines kranken Körpers überwinden konnte.

Eine wesentlich offenere Beurteilung des habsburgischen Herrschers bot der spanische Gesandte Juan de Borja in seinen Berichten aus Prag und Wien. Bereits im Mai 1579, nur wenige Monate nach seiner Ankunft am Kaiserhof, beklagte er sich in seinem Schreiben an den spanischen König Philipp II., dass Rudolf II. wichtige politische Entscheidungen immer wieder verschob und sich nur dem Ballspiel widmete. Die Hauptursache der Gleichgültigkeit und des geringen Interesses am politischen Geschehen sah der gebildete spanische Gesandte in Rudolfs Melancholie, die nach seiner Ansicht zu den psychischen Problemen und zu Rudolfs krankhafter Schlaflosigkeit geführt hatte ${ }^{30}$. Der außerordentliche päpstliche Nuntius Giovanni Battista Castagna bemerkte, dass Juan de Borja tagelang an der Seite Rudolfs II. und dessen Mutter verweilte. Die nicht eingeweihten Beobachter konnten sogar den Eindruck gewinnen, dass er zu dessen eigenem Hofstaat gehöre. Der Spanier erhielt von den Leibkämmerern des Kaisers und wahrscheinlich auch von seinen Ärzten wichtige Informationen ${ }^{31}$.

Unter den Hofärzten, die an der Wende der 1570er zu den 1580er Jahren Rudolf II. behandelten, ragten Johannes Crato von Kraftheim und Julius Alexandrinus von Neustein hervor ${ }^{32}$. Beide gehörten zu den Anhängern traditioneller medizinischer Heil-

${ }_{27}$ Giovanni Delfino an Tolomeo Gallio, Wien, 7.12.1577 - Koller (Bearb.), Nuntiaturberichte (wie Anm. 23) Nr. 122, S. 307-309, hier 309.

${ }^{28}$ Giovanni Delfino an Tolomeo Gallio, Wien, 7.9.1577 - Koller (Bearb.), Nuntiaturberichte (wie Anm. 23) Nr. 86, S. 228-231, hier 228.

${ }_{29}$ Giovanni Delfino an Tolomeo Gallio, Prag, 2.2.1577 - Koller (Bearb.), Nuntiaturberichte (wie Anm. 23) Nr. 11, S. 37-43, hier 42; Giovanni Delfino an Tolomeo Gallio, Wien, 7. 12. 1577 - KolleR (Bearb.), Nuntiaturberichte (wie Anm. 23) Nr. 122, S. 307-309, hier 309.

30 Bohdan Chudoba, Španělé na Bílé hoře [Die Spanier am Weissen Berg] (Praha 1945) 134. Zu Juan Borja vgl. MAREK, La embajada española (wie Anm. 8) 75-82.

${ }^{31}$ Die Aussage Giovanni Battista Castagnas veröffentlichte Rafael García MaHíQues, Empresas Morales de Juan de Borja: imagen y palabra para una iconología (Valencia 1998) 30. Ähnlich MAreK, La embajada española (wie Anm. 8) 78. Zu der Anbindung der Leibkämmerer und Ärzte im Klientelnetz der spanischen Könige vgl. DERs., Klientelní strategie španělských králů na pražském císařském dvoře konce 16. a počátku 17. století [Die Klientelstrategie der spanischen Könige am Prager Kaiserhof am Ende des 16. und zum Beginn des 17. Jahrhunderts]. Český časopis historický 105 (2007) 40-89.

${ }^{32}$ Ivo Purš, Habsburkové na českém trůnu a jejich zájem o alchymii a okultní nauky [Die Habsburger auf dem böhmischen Thron und ihr Interesse für die Alchemie und die okkulten Wissenschaften], in: Alchymie a Rudolf II. (wie Anm. 1) 93-128, hier 109; Ivo Purš-Josef Smolka, Martin Ruland starší a mladší a prostředí císařských lékařu [Martin Ruland der ältere und jüngere und das Milieu der kaiserlichen Ärzte], in: Alchymie a Rudolf II. (wie Anm. 1) 581-605, hier 582f. Johannes Crato von Kraftheim bekannte sich zum Luthertum, pflegte Beziehungen mit der Brüderunität und mit seiner Gesin- 
methoden nach Galen von Pergamon. Sie traten vor Mitte der 1560er Jahre in habsburgische Dienste. Damals kümmerten sie sich um den kranken Ferdinand I. Sie waren tief davon überzeugt, dass eine Behandlung lange Zeit, Wärme, Ruhe und eine allmähliche Reinigung des kranken Organismus benötigte ${ }^{33}$. Noch in den Frühlingsmonaten des Jahres 1578 beriet sich Julius Alexandrinus über geeignete therapeutische Methoden bei der Behandlung der Magenerkrankung Rudolfs II. mit Nicolò Boldoni. Der Leibarzt des spanischen Königs Philipp II. kam für kurze Zeit aus Mailand nach Prag und interessierte sich für die gesundheitlichen Probleme der verwitweten Kaiserin Maria, die an einer schmerzhaften Schwellung der Beine litt ${ }^{34}$.

An der Wende vom Jänner zum Februar 1580 beobachtete der neue päpstliche Nuntius Orazio Malaspina einen deutlichen Wandel im Benehmen Rudolfs II. Nach seinen Berichten hielt sich der Kaiser, während er in der Hauptstadt des Königreichs Böhmen weilte, in der Abgeschiedenheit der Prager Burg auf, erteilte keine Audienzen und unterhielt sich nur gelegentlich mit den engsten Höflingen. Obwohl der Nuntius davon wusste, dass Rudolf II. Erkältung und wiederholte Magenschmerzen plagten, hielt er Rudolfs Krankheit für Melancholie, deren Symptome er mit der Gleichgültigkeit des Kaisers in Zusammenhang brachte ${ }^{35}$. Die häufigsten Symptome der Melancholie - so die zeitgenössische Lehre - waren Trübseligkeit, Faulheit und Langeweile. Der Melancholiker war still, erschöpft und untätig und fand Zuflucht in der Kontemplation und der Kunst, deren Uneindeutigkeit seiner komplizierten inneren Welt den Spiegel vorhielt ${ }^{36}$.

Zur Reinigung des Organismus hatten die Ärzte Rudolf II. ein Abführmittel verschrieben, das er zweimal täglich einnehmen sollte ${ }^{37}$. Sobald sich die Ärzte Ende März 1580 für die Absetzung der Purgiermittel entschieden hatten, empfahlen sie Rudolf II. eine dreiwöchige Trinkkur aus tropischem Holz. Diese diente ebenfalls zur inneren Reinigung seines kranken Körpers ${ }^{38}$. Höchstwahrscheinlich wurde beim Kaiser zu diesem

nung gehörte er zu den Anhängern des humanistischen Irenismus, die nach einer Versöhnung unter verschiedenen Konfessionen suchten. Dazu näher Evans, Rudolf II. a jeho svět (wie Anm. 1) 116f., 119, 126-128, $149 f$.

33 Näher Václav Bưžek, Ferdinand I. ve svědectvích o jeho nemocech, smrti a posledních rozloučeních [Ferdinand I. in den Zeugnissen über seine Krankheiten, den Tod und die letzten Verabschiedungen]. Český časopis historický 112 (2014) 402-431.

${ }^{34}$ Giovanni Delfino an Tolomeo Gallio, Wien, 1.2.1578 - Koller (Bearb.), Nuntiaturberichte (wie Anm. 23) Nr. 140, S. 342-344, hier 342; Giovanni Delfino an Tolomeo Gallio, Wien, 13.4. 1578 - Koller (Bearb.), Nuntiaturberichte (wie Anm. 23) Nr. 161, S. 386-388, hier 388.

35 Orazio Malaspina an Tolomeo Gallio, Prag, 26.1.1580 - Alexander Koller (Bearb.), Nuntiaturberichte aus Deutschland nebst ergänzenden Aktenstücken. Dritte Abteilung 1572-1585. 10. Band. Nuntiaturen des Orazio Malaspina und des Ottavio Santacroce. Interim des Cesare dell'Arena (15781581) (Kempten 2012) Nr. 153, S. 253f., hier 254; Orazio Malaspina an Tolomeo Gallio, Prag, 3.2. 1580 - Koller (Bearb.), Nuntiaturberichte (wie oben) Nr. 156, S. 257 f., hier 257.

36 Zweifellos am bedeutendsten war die Schrift von Robert Burton, The Anatomy of Melancholy, die im Zeitraum der Jahre 1621 bis 1676 achtmal herausgegeben wurde: Robert BurTon, Anatomie melancholie [Die Anatomie der Melancholie] (Praha 2006); vgl. László F. FöLdÉnYI, Melancholie - její formy a proměny od starověku po současnost [Die Melancholie - ihre Formen und Veränderungen seit dem Altertum bis in die Gegenwart] (Praha 2013) 133-170.

37 Orazio Malaspina an Tolomeo Gallio, Prag, 22.3.1580 - Koller (Bearb.), Nuntiaturberichte (wie Anm. 35) Nr. 170, S. 278-281, hier 278f.

38 Orazio Malaspina an Tolomeo Gallio, Prag, 29.3.1580 - Koller (Bearb.), Nuntiaturberichte (wie Anm. 35) Nr. 172, S. 282-284, hier 282. 
Zeitpunkt Syphilis diagnostiziert, da die Trinkkur aus dem tropischen Holz Guayaco zusammen mit Quecksilber und Zinnober im 16. Jahrhundert als das wirkungsvollste Mittel zur Behandlung dieser Krankheit galt ${ }^{39}$. Da die verschriebene Therapie schweißtreibend war, waren Rudolfs Leibärzte davon überzeugt, dass damit die Schadstoffe ausgeschieden würden ${ }^{40}$. Sichtbare Wirkung dieser Trinkkur war die Reduktion des Körpergewichtes, was der Nuntius wahrscheinlich von den Leibkämmerern erfuhr ${ }^{41}$. Erst nach Mitte April 1580 konnte Rudolf II. seine Herrscherpflichten wieder aufnehmen. Als ihn Orazio Malaspina nach seiner Genesung erstmals mit eigenen Augen sah, erschien er ihm außergewöhnlich abgemagert, aber nach seinen Worten hatte er eine gesunde Gesichtsfarbe und strahlte Lebensfreude aus ${ }^{42}$.

Der Gesundheitszustand Rudolfs II. verschlechterte sich jedoch im Herbst 1580 erheblich; er beklagte sich bei seinen Leibärzten nicht nur über eine schmerzhafte Gewebeschwellung des Hodens, sondern auch über nässende Geschwüre am Penis ${ }^{43}$. Ende Oktober nahmen die Ärzte einen Aderlass zur Linderung der Ödeme vor ${ }^{44}$. Nach dieser erfolglosen Therapie entschlossen sich die Ärzte nach langem Überlegen Mitte November zu einem chirurgischen Schnitt im Hodensack, weil sie einen Tumor vermuteten ${ }^{45}$. Der Nuntius verbarg seine Skepsis gegenüber diesem Eingriff nicht, weil sich Rudolf II. schon einer ähnlichen, erfolglosen Operation während seines Spanienaufenthalts, ungefähr zehn oder fünfzehn Jahre zuvor, unterzogen hatte ${ }^{46}$.

Obwohl sich Orazio Malaspina bemühte, unverzüglich Nachricht über den Ablauf und die Ergebnisse der chirurgischen Maßnahme zu erlangen, konnte er dem Staatssekretär des Heiligen Stuhls nur mitteilen, dass der Kaiser sehr geschwächt war, keine Audienzen erteilte und sogar Gespräche mit seinen engsten Höflingen ablehnte ${ }^{47}$. Erst ein Monat nach der Operation gelang es dem Nuntius, von den Leibkämmerern des Kaisers nähere Informationen zu erhalten. Obwohl der Herrscher nach ihren Zeugnissen nicht in Lebensgefahr schwebte, quälten ihn Schmerzen im Genitalbereich. Er war blass, abgemagert und apathisch und blieb meist zu Bett in seiner Kammer, in die keiner,

39 Ulrich von Hutten, De guaici medicina et morbo gallico (Mainz 1524).

40 Orazio Malaspina an Tolomeo Gallio, Prag, 5.4.1580 - Koller (Bearb.), Nuntiaturberichte (wie Anm. 35) Nr. 174, S. 285-288, hier 286; zur Trinkkur aus tropischem Holz näher Alfonso CoRRADI, L'acqua del legno e le cure depurative nel cinquecento (Milano 1884).

${ }^{41}$ Orazio Malaspina an Tolomeo Gallio, Prag, 5.4.1580 - Koller (Bearb.), Nuntiaturberichte (wie Anm. 35) Nr. 174, S. 285-288, hier 286.

${ }^{42}$ Orazio Malaspina an Tolomeo Gallio, Prag, 19.4.1580 - Koller (Bearb.), Nuntiaturberichte (wie Anm. 35) Nr. 180, S. 293-297, hier 297.

${ }^{43}$ Orazio Malaspina an Tolomeo Gallio, Prag, 11.10.1580 - Koller (Bearb.), Nuntiaturberichte (wie Anm. 35) Nr. 231, S. 377f., hier 377.

44 Orazio Malaspina an Tolomeo Gallio, Prag, 25.10.1580 - Koller (Bearb.), Nuntiaturberichte (wie Anm. 35) Nr. 235, S. 384f., hier 384.

45 Orazio Malaspina an Tolomeo Gallio, Rom, 28.11.1580 - Koller (Bearb.), Nuntiaturberichte (wie Anm. 35) Nr. 245, S. 397f., hier 398. Vgl. Josef LeEB (Bearb.), Deutsche Reichstagsakten. Reichsversammlungen 1556-1662. Der Reichstag zu Augsburg 1582. 2 Bde. (München 2007) 99f.

46 Orazio Malaspina an Tolomeo Gallio, Prag, 25.10.1580 - Koller (Bearb.), Nuntiaturberichte (wie Anm. 35) Nr. 235, S. $384 f$., hier 384. Zur spanischen Erziehung Rudolfs II. vgl. JANÁčEK, Rudolf II. a jeho doba (wie Anm. 1) 30-44.

47 Orazio Malaspina an Tolomeo Gallio, Rom, 28.11.1580 - Koller (Bearb.), Nuntiaturberichte (wie Anm. 35) Nr. 245, S. 397f., hier 398. 
außer die Ärzte und die engsten Hofleute, vordringen durfte ${ }^{48}$ : Rudolf wollte in diesem Zustand nicht gesehen werden.

Erst in den ersten Jännertagen 1581 erfuhr der Nuntius, dass der Hodenschnitt vom Ende November des letzten Jahres noch zweimal hatte wiederholt werden müssen. Da der nicht näher bekannte Chirurg den Eingriff beim ersten Mal nicht erfolgreich durchgeführt hatte, wurde ein Chirurg aus Wien beigezogen, der dabei, dem Bericht des Nuntius zufolge, wesentlich geschickter operierte. Die fachliche Autorität für die Genesungszeit des Kaisers war Julius Alexandrinus von Neustein, der meist in Trient weilte und die behandelnden Ärzte in Briefen anwies, welche Maßnahmen sie zur Eiterabsonderung aus dem Hodenschnitt ergreifen sollten, um nicht eine Kanüle in die Wunde einführen zu müssen ${ }^{49}$.

Mitte Februar 1581 erschöpften Rudolf die Schmerzen dermaßen, dass er nicht an der Eröffnung des böhmischen Landtags teilnehmen und dort gemäß der Tradition auch nicht die königliche Proposition vorlesen konnte ${ }^{50}$. Als Anfang März der bayerische Herzog Ferdinand von Wittelsbach Kaiser Rudolf II. einen Besuch abstattete, traute er beim Anblick des kranken Kaisers seinen Augen nicht. Rudolfs Körper war angeschwollen, seine Hautfarbe ähnelte eher einem verstorbenen als einem lebendigen Menschen ${ }^{51}$. Diese Beschreibung des bayerischen Herzogs übernahmen und verbreiteten die in Prag residierenden ausländischen Diplomaten unmittelbar. Aus Graz reiste deshalb der Onkel des Kaisers Erzherzog Karl an, der Erzherzog Ferdinand in Innsbruck vom besorgniserregenden Gesundheitszustand Rudolfs unterrichtete ${ }^{52}$. Die beiden Onkel Rudolfs II. waren sich der möglichen politischen Folgen einer lebensgefährlichen Erkrankung des Kaisers bewusst. Beide brachten entschlosseneren Willen und Bereitschaft für eventuelle Nachfolgeverhandlungen für den Kaiser- und Königsthron zum Ausdruck, als dies etwa Albrecht, Ernst, Matthias und Maximilian, die jüngeren Brüder Rudolfs II., taten ${ }^{53}$.

Orazio Malaspina genügte die Mitteilung des bayerischen Herzogs nicht. Er holte Informationen über den Krankheitsverlauf des Kaisers bei dessen Leibärzten und bei den Leibkämmerern ein. Anfang März gelangte der Nuntius zur Überzeugung, dass sich Rudolfs Gesundheitszustand rasch veränderte. Trotz der Operation und Therapierung der nässenden Geschwüre am Geschlechtsorgan gelang es den Ärzten nicht, die Entzündung, welche hohes Fieber, Übellaunigkeit und Desinteresse des Kaisers hervorrief, in den Griff zu bekommen. In den Augen der Ärzte litt Rudolf II. unter immer mehr stärkeren Anfällen von Schwermut. Aufgrund dieser exakten Informationen schloss Orazio Malaspina eine ernsthafte Lebensgefahr für den Kaiser nicht aus und meldete seine Befürchtungen nach Rom $^{54}$.

48 Orazio Malaspina an Tolomeo Gallio, Prag, 20.12.1580 - Koller (Bearb.), Nuntiaturberichte (wie Anm. 35) Nr. 250, S. 402-404, hier 402.

49 Orazio Malaspina an Tolomeo Gallio, Prag, 3.1.1581 - Koller (Bearb.), Nuntiaturberichte (wie Anm. 35) Nr. 254, S. 405-407, hier 406.

50 Sněmy české od léta 1526 až po naši dobu [Die böhmischen Landtage seit dem Jahre 1526 bis in unsere Zeit] 6 (Praha 1890) 1; JANÁČEK, Rudolf II. a jeho doba (wie Anm. 1) 191.

${ }^{51}$ LeEb (Bearb.), Deutsche Reichstagsakten (wie Anm. 45) $99 \mathrm{f}$.

52 Orazio Malaspina an Tolomeo Gallio, Prag, 7.2.1581 - Koller (Bearb.), Nuntiaturberichte (wie Anm. 35) Nr. 262, S. 415-417, hier 416.

53 JANÁČEK, Rudolf II. a jeho doba (wie Anm. 1) $191 \mathrm{f}$.

54 Orazio Malaspina an Tolomeo Gallio, Prag, 7.3.1581 - Koller (Bearb.), Nuntiaturberichte (wie Anm. 35) Nr. 270, S. 425-427, hier $426 f$. 
Während des April und der ersten Hälfte des Mai 1581 verbreitete sich aus Prag nach Innsbruck, München, Rom, Graz, Wien, aber auch in andere europäische Hauptstädte ein Bild des schwer kranken Kaisers, der acht Monate lang in der Abgeschiedenheit seiner Kammern auf der Prager Burg unter starken Schmerzen im Genitalbereich und einer zunehmenden Anzahl an Geschwüren am Penis, weiters an Fieber, Übelkeit und Körperschwäche litt. Der päpstliche Nuntius am Kaiserhof stellte sich deshalb die Frage, ob die Ärzte die richtige Therapie gewählt hatten, wenn weder chirurgische Maßnahmen noch Abführmittel noch verschiedene Trinkkuren zur Reinigung des Organismus und zur Heilung der eiternden Entzündungsherde halfen ${ }^{55}$. Erst in der zweiten Hälfte des Mai 1581 wurde es den Ärzten klarer, dass das ständige Fieber mit dem Eiter in den entzündeten Geschwüren zusammenhing. Sie beschlossen daher, die Geschwüre am Penis und am Hoden nicht nur durch einen weiteren chirurgischen Eingriff zu öffnen, sondern führten, nach langer Erwägung, kleine Kanülen in die Wunden ein, durch die der Eiter abfließen konnte ${ }^{56}$. Es dauerte allerdings noch weitere drei Monate, bis sich Rudolf II. so wohl fühlte, dass er die Prager Burg verlassen und sich Ende August 1581 mit seinem Gefolge auf Wildjagd nach Brandeis an der Elbe aufmachen konnte ${ }^{57}$.

Obwohl die Werke der Maler, Bildhauer, Kupferstecher und Medailleure aus den 1590er Jahren Rudolf II. als energischen Monarchen, als kühnen christlichen Kämpfer und als Hauptbeschützer Europas im Krieg gegen die Andersgläubigen darstellen, wich das tatsächliche Aussehen des Kaisers in Folge der dauernden gesundheitlichen Beschwerden von diesem Ideal deutlich ab. Während der Audienzen konnten die Besucher des Kaiserhofes einen Mann mit eher kräftigem Körperbau und mit gerötetem Gesicht sehen. Auch wenn Rudolf II. sich nach dem modischen spanischen Stil kleidete, blieb den neugierigen Beobachtern nicht verborgen, dass sein Körper dicht mit Geschwüren bedeckt war. Nach dem Zeugnis Fynes Morysons aus dem Jahre 1592 kursierten „unter den Deutschen und Tschechen Gerüchte darüber, dass der Kaiser sich den Venuskriegen ergebe, wovon er am Körper zahlreiche Schrammen und eine verheimlichte Kontusion habe“ 58 . Während der 1590 er Jahre verschlimmerten wiederholte Katarrhe der oberen Atemwege (catarro), psychische Störungen und besonders häufige Anfälle der Schwermut (bumori malinconici), die den Kaiser daran hinderten, seine Herrscherpflichten auszuüben, den Gesundheitszustand Rudolfs II. ${ }^{59}$.

In Hinblick auf die ungelöste Frage der Nachfolge im Römisch-Deutschen Reich bereitete Rudolfs kritischer Gesundheitszustand den Mitgliedern der spanischen Linie

55 Ruprecht von Störzing an Wilhelm von Wittelsbach, Prag, 13.4.1581 - Bayerisches Hauptstaatsarchiv München, Kurbayern Äußeres Archiv, Sign. 4344; Orazio Malaspina an Tolomeo Gallio, Prag, 2.5.1581 - Koller (Bearb.), Nuntiaturberichte (wie Anm. 35) Nr. 290, S. 455f., hier 456; Orazio Malaspina an Tolomeo Gallio, Prag, 9.5.1581 - Koller (Bearb.), Nuntiaturberichte (wie Anm. 35) Nr. 293, S. 460f., hier 460.

56 Orazio Malaspina an Tolomeo Gallio, Prag, 16.5.1581 - Koller (Bearb.), Nuntiaturberichte (wie Anm. 35) Nr. 295, S. 464f., hier 465.

57 Ottavio Santacroce an Tolomeo Gallio, Prag, 29.8.1581 - Koller (Bearb.), Nuntiaturberichte (wie Anm. 35) Nr. 333, S. 537-540, hier 537; Leeb (Bearb.), Deutsche Reichstagsakten (wie Anm. 45) $99 \mathrm{f}$.

58 Fynes Moryson-John Taylor, Cesta do Čech (wie Anm. 4) 80 (in freier deutscher Übersetzung).

59 Davon zeugen die Schreiben, die Cesare Speciano nach Rom schickte. Seine Berichte bereitet Alena Pazderová für die Veröffentlichung vor, der die Autoren zu aufrichtigem Dank für die Vermittlung des Inhalts der Briefe Nr. 83/2, 204, 264, 553/1, 631, 663, 857, 868/4 verpflichtet sind. 
des Hauses Habsburg große Sorgen. Obwohl auf dem Regensburger Reichstag 1594 neben den katholischen geistlichen Kurfürsten auch der Herzog von Sachsen Friedrich Wilhelm versprach, die Habsburger zu wählen, lehnten es die Ratgeber des spanischen Königs ab, sich auf die Zusage des Protestanten zu verlassen. An besonderer Bedeutung gewann die Sukzessionsfrage nach 1600, als Rudolf II. neben der Syphilis und dem Schwermut auch die Apoplexie befiel ${ }^{60}$. Die gesundheitlichen Beschwerden des Kaisers waren dermaßen ernst, dass sie den Beobachtern lebensgefährlich erschienen ${ }^{61}$.

Die zeitgenössischen Beobachter an der Wende der 1570er zu den 1580er Jahren beschrieben die Symptome von Rudolfs Erkrankung am häufigsten mit dem Wort Melancholie. Wobei sich der Inhalt dieser Bezeichnung änderte. Ursprünglich umfasste die Melancholie nur sichtbare Veränderungen im Verhalten des kranken Herrschers, zu denen Apathie, Unentschlossenheit, Misstrauen, Gereiztheit und immer häufiger Neigung zum eigenbrötlerischen Leben zählten. Seit Ende der 1590er Jahre, als sich der Gesundheitszustand des Kaisers erheblich verschlimmerte ${ }^{62}$, wurden die Ursachen der Schwermut im physiologischen und psychischen Bereich gesucht ${ }^{63}$. Der spanische Gesandte am Kaiserhof in Prag Guillén de San Clemente sah im Frühling 1603 unter Bezug auf das Fachgutachten des kaiserlichen Arztes und Beichtvaters Johannes Pistorius die Ursache von Rudolfs Melancholie in den Destillationen, mit denen man im Spanischen dieser Zeit auch die Dämpfe bezeichnete, die der Kaiser nach dem Zeugnis der zeitgenössischen Beobachter einatmete. Gleichzeitig benutzte man diesen Ausdruck zur Bezeichnung des schädlichen Verhaltens von Flüssigkeiten im menschlichen Organismus ${ }^{64}$. Der florentinische Gesandte Roderico Alidosi nahm zwei Jahre später an, dass die Melancholie mit dem ungezügelten Sexualleben des Herrschers zusammenhing ${ }^{65}$.

Während der Herbst- und Wintermonate 1608 zählte der Reichshofrat Johann Anton Barvitius, der nicht nur persönliche Kontakte zu einer Reihe von Dichtern, Astronomen und Naturwissenschaftlern in den Diensten Rudolfs II. pflegte, sondern auch Begleiter ausländischer Gesandter, die in der Hauptstadt des Königreichs Böhmen eintrafen, war, zu den härtesten Kritikern von Rudolfs Gleichgültigkeit in politischen Dingen. Barvitius war ein eifriger Katholik, der große Geldsummen für Marienstatuen und Altäre in einigen Prager Kirchen ausgegeben hatte ${ }^{66}$. Im Umkreis der Personen, mit

${ }^{60} \mathrm{Zu}$ dem zeitgenössischen Inhalt der Bezeichnung Apoplexie näher Sebastián de CovarRubias Horozco, Tesoro de la lengua castellana o española (Madrid 1611) 197: „Apoplexia es una enfermedad tan peligrosa como notoria de que muchos mueren repentinamente: dicen los médicos ser una estupefacción y pasmo de los niervos de todo el cuerpo con privación de sentidos y movimiento y assí al tal paciente entre otros beneficios que le hacen es darle tormento de cuerdas."

${ }_{61}$ Documenta Polonica (wie Anm. 7) 164-166.

62 JanÁČEK, Rudolf II. a jeho doba (wie Anm. 1) 332f., 342-344.

63 Sněmy české (wie Anm. 50) 10 (Praha 1900) 92-96, hier 92f. (Kurzer Discurs, wie der Röm. Kais. Mt. in ihrem itzigen Anliegen vor ihr Person und sonsten zu helfen sein möcht, Oktober 1600); NA, SO, CA - Simancas, Kart. 1 (Guillén de San Clemente an Philip III., Prag, 19.4. 1603); Campori (Bearb.), Roderico Alidosi, Relazione di Germania (wie Anm. 4) 6; MatoušeK, K problému (wie Anm. 15) 344.

${ }^{64}$ NA, SO, CA - Simancas, Kart. 1 (Guillén de San Clemente an Philipp III., Prag, 19.4. 1603). Zum zeitgenössischen Inhalt der Bezeichnung destilación vgl. Diccionario de la lengua castellana, en que se explica el verdadero sentido de las voces, su naturaleza y calidad, con las phrases o modos de hablar, los proverbios o refranes, y otras cosas convenientes al uso de la lenqua [...]. Compuesto por la Real Academia Española. 3 (Madrid 1732) 235. Zu Johann Pistorius Stloukal, Portrét (wie Anm. 15) 8f.; PuršSMOLKa, Martin Ruland starší a mladší (wie Anm. 32) 581.

${ }^{65}$ Campori (Bearb.), Roderico Alidosi, Relazione di Germania (wie Anm. 4) 6.

${ }^{66}$ Der Hof Kaiser Rudolfs II. (wie Anm. 7) 212, 215f.; Stefan Ehrenpreis, Kaiserliche Gerichts- 
denen er sich regelmäßig traf, kam dem päpstlichen Nuntius Antonio Caetani eine privilegierte Stellung zu. Während dieser gemeinsamen Unterredungen informierte Johann Anton Barvitius den Nuntius gelegentlich über die Erkrankung des Kaisers, die er gewöhnlich unter Melancholie subsumierte ${ }^{67}$. Den physiologischen Symptomen, von denen er keine genaueren Informationen hatte, schenkte er dagegen keine Beachtung. Den Kaiser schilderte Barvitius als einen vollkommen unzuverlässigen und unentschlossenen Menschen, der infolge seiner Erkrankung die Amtsgeschäfte des Kaiserhofs bremse. Wenn sich Rudolf in Ausnahmefällen dann doch entschloss, eine lang aufgeschobene politische Entscheidung zu treffen, rief er durch unüberlegte Schritte Verwirrung und Chaos hervor ${ }^{68}$. Rudolfs Wankelmütigkeit und sein krankhaftes Misstrauen bekam Johann Anton Barvitius am eigenen Leibe zu spüren. Er beklagte sich beim päpstlichen Nuntius darüber, dass ihn der Herrscher sogar mehrmals in der Nacht wecken ließ: Der kranke Kaiser fürchtete sich wahrscheinlich vor den Anschlägen seiner Feinde, deshalb suchte er einen Vertrauten, der ihn beruhigen sollte ${ }^{69}$. Die kritischen Worte von Johann Anton Barvitius über die krankhafte Melancholie Rudolfs II. übermittelte der Nuntius Antonio Caetani in seinen Berichten aus Prag nach Rom, wo sie in die Hände des Kardinals Scipio Borghese gelangten. Ende der 1610er Jahre vermittelten diese Berichte ein Bild von Rudolf II., in dem deutlich wurde, dass der Kaiser den Willen zur Überwindung seiner Krankheiten verloren hatte.

Ungeachtet dessen beaufsichtigten in den letzten zehn Jahren von Rudolfs Leben fünf bis sieben außerordentlich gebildete Ärzte ${ }^{70}$, mit denen ihn enge persönliche Beziehungen verbanden ${ }^{71}$, den sich immer mehr verschlimmernden Gesundheitszustand des Kaisers. Da sie die Gesundheit des Kaisers für ein ärztliches Geheimnis hielten, veröffentlichten sie keine Informationen über die Ursachen und den Verlauf seiner Erkrankungen $^{72}$. Die reservierte Haltung der Ärzte bestätigten auch einige ausländische Gesandte, die Zugang zum unmittelbaren Umfeld des Herrschers besaßen, wo sie Einblick in die für den Kaiser aufgewendete medizinische Pflege erhielten. Nach den Berichten Pierre Bergerons, der den Kaiserhof im Sommer 1600 als Sekretär der diplomatischen Gesandtschaft des französischen Königs Heinrich IV. besuchte, durften die Leibärzte des Herrschers nur im Falle einer außerordentlichen Verschlimmerung von Rudolfs Gesundheitszustand berichten ${ }^{73}$.

Aus den Aussagen der Personen, die in den ersten Jahren des 17. Jahrhunderts bei den Audienzen wie auch bei den privaten Unterredungen den Kaiser zu Gesicht bekamen, geht hervor, dass sich der Verlauf der chronischen neurologischen Erkrankungen

barkeit und Konfessionskonflikt. Der Reichshofrat unter Rudolf II. 1576-1612 (Schriftenreihe der Historischen Kommission der Bayerischen Akademie der Wissenschaften 72, Göttingen 2006) 291; Michal ŠronĚK, Johann Barvitius als Mäzen im Rudolfinischen Prag. Studia Rudolphina 8 (2008) 49-57.

67 Antonio Caetani an Scipio Borghese, Prag, 15.9.1608 - Tomáš ČERnušák (Bearb.), Epistulae et acta nuntiorum apostolicorum apud imperatorem 1592-1628. Tomus IV. Epistulae et acta Antonii Caetani 1607-1611. Pars IV. September 1608 - Junius 1609 (Praha 2013) Nr. 21, S. 23f., hier 24.

68 Antonio Caetani an Scipio Borghese, Prag, 20.10.1608 - Černušák (Bearb.), Epistulae (wie Anm. 67) Nr. 73, S. 68f.

${ }^{69}$ Antonio Caetani an Scipio Borghese, Prag, 26.10.1608 - ČErnušÁK (Bearb.), Epistulae (wie Anm. 67) Nr. 81, S. 74-76, hier 75.

70 Purš-SMOlKa, Martin Ruland starší a mladší (wie Anm. 32) 582.

71 Evans, Rudolf II. a jeho svět (wie Anm. 1) 243-249.

72 Purš-SMolka, Martin Ruland starší a mladší (wie Anm. 32) 581.

73 Tři francouzští kavalíri (wie Anm. 4) 47. 
und Infektionen allmählich auf Rudolfs Haltung und Aussehen auszuwirken begannen $^{74}$. Bei der Sitzung des böhmischen Landtags am 23. Mai 1608 entging es beispielsweise Wolf Nowohradsky von Kolowrat nicht, dass das Gehen dem Kaiser offensichtlich Probleme bereitete. In seinem Schreiben an Peter Wok von Rosenberg schilderte er ausführlich ${ }^{75}$, dass der Monarch müde aussah und wegen der Erkrankung seiner Beine unter Schmerzen und nur mit großer Überwindung über die drei Treppen hinauf zum Podest (bzw. herunter) im Landtagsgebäude auf der Prager Burg steigen konnte. Die Ursache der ungewöhnlichen Körperschwäche des Kaisers und seiner Gehbeschwerden sah Wolf Nowohradsky von Kolowrat vor allem im sich zuspitzenden dynastischen Konflikt zwischen Kaiser Rudolf II. und seinem jüngeren Bruder Erzherzog Matthias ${ }^{76}$. Gleichzeitig bemerkten ausländische Gesandte am Kaiserhof, dass Rudolf II. an ständigen Schlafstörungen litt. Er ging am frühen Abend zu Bett, schlief jedoch sehr wenig, auch weil er sich vor langem Schlaf fürchtete. Er wachte oft in der Nacht, durch Alpträume geweckt, ganz verschwitzt auf und verließ unverzüglich das Bett. Sein Leibarzt Ottavio Roboreto von Freiberg und der Kämmerer Adam von Nürnberg mussten ihn in diesen Fällen beruhigen und verbrachten deshalb die Nacht in der Antekammer des kaiserlichen Schlafzimmers ${ }^{77}$.

Als der spanische Gesandte Baltasar Zúñiga in seinem Bericht nach Madrid vom 9. August 1608 den Ablauf seiner ersten Audienz am Kaiserhof in Prag beschrieb, schilderte er Rudolf II. als menschliches Wrack. Obwohl das Gespräch in Spanisch stattfand, verstand der Diplomat die Worte des Kaisers nicht, weil dessen Stimme außergewöhnlich schwach und leise war. Der Gesandte war auch über die Gleichgültigkeit des geistig und körperlich erschöpften Kaisers entsetzt. Das absolute Desinteresse an den Nachrichten aus Madrid und an den spanischen Verwandten hielt er für den Ausdruck der kaiserlichen Agonie, denn das Interesse an der Gesundheit der Verwandten gehörte zu den grundlegenden gesellschaftlichen Konventionen der spanischen Hofkultur, und dementsprechend galt eine Missachtung dieser Regel als grober Verstoß gegen die Hofetikette. Rudolfs schlechter Gesundheitszustand erlaubte es ihm, so Baltasar Zúñiga, nicht, seinen Herrscherpflichten nachzukommen, deshalb tauchten immer wieder in den diplomatischen Berichten aus Prag nach Madrid Vorschläge über eine Regierungsunfähigkeit Rudolfs auf ${ }^{78}$. Die Frage der Nachfolge Rudolfs II. stellten für den spanischen Gesandten alle anderen Aufgaben seiner Mission in den Schatten ${ }^{79}$.

Ähnlicher Ansicht bezüglich der herrscherlichen Fähigkeiten Rudolfs II. waren die Repräsentanten des Heiligen Stuhls. In der Zeit, als der Herrscher dem Erlass des Majestätsbriefes zur Glaubensfreiheit zugestimmt hatte, überbrachten die römischen Gelehrten Papst Paul V. einige fachliche Gutachten, in denen sie sich gründlich mit dem Gedanken über eine mögliche Absetzung des Kaisers befassten. Unüberlegten Schritten des geistesgestörten Herrschers wollte man durch die Ernennung eines Mitherrschers vorbeugen, der alle seine Entscheidungen beaufsichtigen und lenken sollte. In Rom

74 Wolf Novohradsky von Kolowrat an Peter Wok von Rosenberg (Prag, 22. 1. 1602) - SOA Třeboň, Historica Třeboň, Sign. 6007.

75 SOA Třeboň, Historica Třeboň, Sign. 6134 (Prag, 27.5. 1608).

76 Ein Bruderzwist im Hause Habsburg (wie Anm. 13).

77 CAmpori (Bearb.), Roderico Alidosi, Relazione di Germania (wie Anm. 4$) 6$.

78 NA, SO, CA - Simancas, Kart. 1 (Baltasar de Zúñiga an Philipp III., Prag, 9. 8. 1608).

79 Rubén Gonzáles Cuerva, Baltasar de Zúñiga. Una encrucijada de la monarquía hispana (15991622). (Madrid 2012) 231-357. 
herrschte langfristig die Überzeugung vor, dass die Taten Rudolfs nicht aus böser Absicht geschahen, sondern dessen Nachlässigkeit und Verrücktheit (mente emota) widerspiegelten ${ }^{80}$.

Vor Ende Dezember 1611 berichteten der päpstliche Nuntius Giovanni Battista Salvago und Tomasso Roncaroli, der in den Diensten des Herzogs von Parma und Piacenza stand, nahezu gleichlautend über den körperlichen und psychischen Zustand Rudolfs II. Ihren wachsamen Augen fielen die starken Schmerzen des Kaisers beim Gehen auf. Beide Gesandten sahen die Ursache dieser Beschwerden in der Wassersucht in den Beinen, die schon länger stark angeschwollen waren. Dieses „Bulletin“ ergänzten sie mit den Informationen über Rudolfs Schlaflosigkeit, über seine Depressionen und die Hitzewallungen ${ }^{81}$. Balthasar Zúñiga beobachtete sogar, dass der fieberhitzige Rudolf II. mitten im strengen Winter Anfang des Jahres 1612 befahl, das Feuer im Kamin zu löschen und die Fenster aufzumachen ${ }^{82}$. Einige Gesandte nannten, wenn es um die Ursachen für die Krankheiten des Kaisers ging, seine erotischen Eskapaden und sein fortgesetztes ungezügeltes Sexualleben. Ihre Behauptungen stützten sie auf die Aussagen von ungenannten Augenzeugen, die davon erzählten, dass Ende Dezember 1611 „zwei hübsche maurische Huren“" den Kranken in seinen Gemächern besucht hätten, die er nackt zu sehen wünschte. Obwohl Tomasso Roncaroli wie auch Giovanni Battista Salvago beim Erhalten solcher Nachrichten ihre Verlegenheit nicht verbergen konnten, schlossen sie deren Inhalt in ihre diplomatischen Berichte ein, die das Bild vom kränklichen Kaiser in den Augen der Briefempfänger auf der Apenninenhalbinsel noch vertieften ${ }^{83}$.

Vor Ende Dezember 1611 taucht ein Novum in der Berichterstattung der Diplomaten über die Behandlung von Rudolfs Krankheiten auf. Die Gesandten schrieben, dass sich der Kaiser nach langem Zögern endlich für die Einnahme der von seinen Leibärzten verschriebenen Arzneimittel, die vor allem seinen kranken Organismus wieder reinigen sollten, entschieden hätte. Immer wenn Rudolf diese leicht giftige Antimon- und Kalisalzlösung trank, traten nach dem Zeugnis Tomasso Roncarolis würgendes Erbrechen und übermäßiges Schwitzen auf ${ }^{84}$. Der Abscheu des Kaisers gegen die erwähnte Medikation mit ihren viel zu drastischen Wirkungen erscheint nachvollziehbar. Die Giftigkeit dieser Medikamente war den Zeitgenossen sehr wohl bekannt, und an den bedeutenden medizinischen Fakultäten gab es sogar Stimmen, die ihr Verbot forderten. Als Rudolf II.

${ }^{80}$ NA, SO, CA - Vatikán, Ř́m, Itálie, Kart. 8, Sign. 2 a-c (vgl. Sign. 2 a De imperatore deponendo vel coadiutore ei dando, undatiert). Näher Tomáš Č́Enušák, Die päpstliche Politik in Mitteleuropa vor und nach dem Majestätsbrief - Wandel oder Kontinuität?, in: Religion und Politik im frühneuzeitlichen Böhmen (wie Anm. 13) 55-61, hier 60f.

${ }^{81}$ NA, SO, CA - Vatikán, Rím, Itálie, Kart. 223 (Tomasso Roncaroli an Ranuccio Farnese, Herzog von Parma und Piacenza, Prag, 26.12.1611); Kart. 109 (Giovanni Battista Salvago an Kardinal Scipio Caffarelli-Borghese, Prag, 26.12.1611).

82 NA, SO, CA - Simancas, Kart. 11 (Baltasar de Zúñiga an Antonio de Aróstegui, Prag, 20.1.1612).

${ }^{83}$ NA, SO, CA - Vatikán, Ř́m, Itálie, Kart. 223 (Tomasso Roncaroli an Ranuccio Farnese, Herzog von Parma und Piacenza, Prag, 26.12.1611); Kart. 109 (Giovanni Battista Salvago an Kardinal Scipio Caffarelli-Borghese, Prag, 26.12.1611); das Zitat in der freien deutschen Übersetzung aus dem erwähnten Brief Tomasso Roncarolis.

${ }^{84}$ NA, SO, CA - Vatikán, Rím, Itálie, Kart. 223 (Tomasso Roncaroli an Ranuccio Farnese, Herzog von Parma und Piacenza, Prag, 26.12.1611); Wolf-Dieter MÜller-JahnCKe-Christoph FriedrichJulius Paulus, Geschichte der Arzneimitteltherapie (Stuttgart 1996) 32-40, 55-58, 62-66. 
Ende des Jahres 1611 schließlich einwilligte, diese Arzneimittel einzunehmen, zeigt das schon seine Hoffnungslosigkeit ${ }^{85}$.

Symptome des Verfalls, die die Personen in der unmittelbaren Umgebung des Kaisers bemerkten, werden durch die Leibärzte Ottavio Roboreto aus Freiberg und Simon Perger aus Augsburg in ihrer ausführlichen Krankheitsbeschreibung im Obduktionsbefund bestätigt $^{86}$. Beide Ärzte vermerkten dort, dass Rudolf II. seit der Mitte des Jahres 1611 wiederholte Anfälle würgenden Hustens, hohen Fiebers, Härtung der Bauchhöhle und Wassersucht in den Füßen plagten. Beim Husten warf er dicken Schleim und schwarze Blutklumpen, die nach Fäulnis rochen, aus. Hohes Fieber, bei dem die Wangen des Kaisers, über die ihm der Schweiß floss, gerötet waren, wechselte mit Schüttelfrost. Da Rudolf II. wegen seines Gesundheitszustandes wenigstens ein halbes Jahr vor seinem Tod nicht mehr einschlafen konnte, war er ständig schlaff und müde. Der geschwächte Organismus litt zudem unter mangelnder Nahrung, weil Rudolf II. immer weniger aß. Nach der Mitte des Oktober 1611 empfand der Herrscher akuten Schmerz am linken Hodensack, begleitet von ungewöhlich hohem Fieber ${ }^{87}$.

Als beste Behandlungsmöglichkeit galt nach dem Attest Ottavio Roboretos und Simon Pergers Ende Oktober 1611 die Ruhe für den Kranken. Nach der galenschen Tradition schlugen die Ärzte nicht nur Ruhe im Bett, sondern generell eine Beruhigung des kranken Organismus vor, um das innere Gleichgewicht der Säfte wieder herzustellen. Aderlass sollte durchgeführt, Klistiere verabreicht, Abführmittel und verschiedene Latwerge eingenommen werden. Durch diese Wege wurden nach den zeitgenössischen medizinischen Kenntnissen „die aufwallenden Körpersäfte mit den Unreinigkeiten“ ausgeschieden ${ }^{88}$. Die therapeutische Wirkung der gewählten Behandlungsmethoden überprüften die Ärzte, indem sie dem Kaiser regelmäßig den Puls fühlten, der Mitte November 1611 kaum Standardwerte aufwies. Trotz der kurzfristigen Verbesserung von Rudolfs Allgemeinzustand rief die Wahl der Heilverfahren bei einigen hohen Hofamtsträgern Zweifel hervor ${ }^{89}$.

Einwände gegen die fachlichen Kompetenzen der kaiserlichen Leibärzte und die gewählte Therapie äußerten vor allem der Obersthofkämmerer Ulrich Desiderius Pruskowsky von Pruskau und der Reichshofrat Johann Anton Barvitius ${ }^{90}$. Ihr Misstrauen galt wahrscheinlich weniger der Qualifikation der berühmten Ärzte, sondern beruhte auf den politischen und konfessionellen Gegensätzen am Hof Rudolfs II., an dem sich zwei feindliche Lager der Reichskatholiken und der Protestanten gegenüberstanden ${ }^{91}$. Die Leibärzte waren nicht nur dem Kaiser verpflichtet, sondern einige von ihnen unterhielten auch enge Verbindungen zu anderen Repräsentanten der Habsburgerdynastie,

85 NA, SO, CA - Vatikán, Ř́m, Itálie, Kart. 109 (Giovanni Battista Salvago an Kardinal Scipio Caffarelli-Borghese, Prag, 19.12.1611).

${ }^{86}$ HHStA, FA, Kart. 65. Für die Übersetzung des umfangreichen Arztberichtes vom 26.1. 1612 aus dem Lateinischen, der bisher nicht zum Gegenstand eines intensiveren Forscherinteresses wurde, bedanken sich die Autoren bei Rostislav Smíšek.

87 Ebd.

88 Ebd. (in freier deutscher Übersetzung).

89 Archivio di Stato di Torino, Lettere ministri, Austria, mazzo 6, Praga 1601-1607 (Gieronimo Lovencito an Karl Emanuel nach Torino, Regensburg, 10.4.1612).

90 HHStA, FA, Kart. 65.

${ }^{91}$ Anton Chroust (Bearb.), Briefe und Akten zur Geschichte des Dreissigjährigen Krieges in den Zeiten des vorwaltenden Einflusses der Wittelsbacher. Zehnter Band - Der Ausgang der Regierung Rudolfs II. und die Anfänge des Kaisers Matthias (München 1906) 214f., 221-225, 237-239. 
vor allem zum König von Spanien ${ }^{92}$. Ulrich Desiderius Pruskowsky und Johann Anton Barvitius hegten sogar den Verdacht, dass die behandelnden Ärzte eher die machtpolitischen Interessen ihrer auswärtigen Patrone als die sorgfältige Pflege des Herrschers im Auge hatten. Die feste Verankerung einiger kaiserlicher Ärzte im Klientelnetz der spanischen Habsburger bestätigte der Fall von Johann Pistorius, der vertrauten Briefwechsel mit Erzherzog Albrecht in Brüssel führte und gleichzeitig eine Rente vom spanischen König Philipp III. aus Madrid bezog ${ }^{93}$.

Zur Reinigung des kranken Körpers und als Anregung zum Schwitzen diente ab Dezember 1611 das Trinken von Salzlösungen mit verschiedenen chemischen Substanzen, was auch dem wachsamen Auge der ausländischen Gesandten nicht entging ${ }^{94}$. Obwohl der Herrscher täglich mehrere Liter dieser Flüssigkeiten zu sich nahm, um seinen großen Durst zu löschen, schied er nur geringe Mengen schwarzen Urins aus. Infolge der Wassersucht im kranken Körper und der fortschreitenden Syphilis vergrößerten sich die Ödeme in den unteren Extremitäten erheblich. Die durchgeführten Punktionen linderten diese heftigen und schmerzhaften Anschwellungen kaum, sondern trugen nur zur Verbreitung der Entzündungsherde bei ${ }^{95}$. In den nässenden Bläschen der rissigen und geröteten Haut, die voll von Eiter waren, verbreitete sich rasch die Gangrän. Auch wenn die Ärzte empfahlen, die eiternden offenen Wunden an den angeschwollenen Beinen im Knie- und Oberschenkelbereich mit antiseptisch wirkenden Arzneimitteln (ein Pulver aus Magenstein, Beifuß und einer Heilpflanze namens Schlangenmord) einzuschmie$\operatorname{ren}^{96}$, forderte der Herrscher uneinsichtig, dass die Gangrän weiterhin mit Wunderölen und anderen alchimistischen Heilmitteln behandelt werden sollte, wie es ihm einst der berühmte schottische Alchemist Alexander Seton empfohlen hatte ${ }^{97}$.

Nach dem Zeugnis Ottavio Roboretos und Simon Pergers war der geschwächte und unter heftigen Schmerzen leidende Rudolf II. bei seinem Tod am Morgen zwischen sechs und sieben Uhr des 20. Jänner 1612 bei klarem Verstand ${ }^{98}$. Obwohl bezeugt wur-

92 MareK, Klientelní strategie (wie Anm. 31) 69-72.

93 Archives Générales du Royaume Bruxelles, Archives de la Secrétairerie d'Etat Allemande, I 074, Sign. 465. Als Belohnung für den Dienst an der spanischen Krone wurde Johann Pistorius vom König im Jahre 1603 sogar eine Rente in Höhe von 1.000 Dukaten jährlich erteilt. Ebd. I 074, Sign. 465, fol. 71 (Valladolid, 2.7. 1603). Die gleiche Rente bestätigte Philipp III. Johann Pistorius noch in einem Brief an den Statthalter von Mailand Pedro Enríquez de Acevedo, Grafen de Fuentes. Dazu ebd. fol. 74 (Ventosilla, 31.5. 1608).

${ }^{4}$ NA, SO, CA - Vatikán, Ř́m, Itálie, Kart. 223 (Tomasso Roncaroli an Ranuccio Farnese, Herzog von Parma und Piacenza, Prag, 26.12.1611).

95 NA, Gindelyho sbírka [Gindelys Sammlung], Kart. 4, Heft 21 (Avisos de Praga, 21. 1. 1612).

96 HHStA, FA, Kart. 65.

${ }^{7}$ JanÁČEK, Rudolf II. a jeho doba (wie Anm. 1) 502; Purš-SMOLKa, Martin Ruland starší a mladší (wie Anm. 32) 604f.; Stanton J. Linden, The Alchemy Reader. From Hermes Trismegistus to Isaac Newton (Cambridge 2003) 174; Antonio Las Heras, Alquimía. Historia, rituales y fórmulas (Buenos Aires 2005) 37 (Alexander Seton starb 1604).

${ }^{8}$ HHStA, FA, Kart. 65; ASMa, L'archivio dei Gonzaga di Castiglione delle Stiviere, busta 246, Rodolfo Petrocini 1611-1616 (Rodolfo Petrocini an Francesco Gonzaga di Castiglione delle Stiviere, Prag, 21. 1. 1612); Abraham Hosmann, Lacrymae oder Klag- und Trawerschreiben wegen des tödlichen Abschiedes des Aller Durchlautigsten [...] Herrn Rudolphi des Anderen [...] (Leipzig 1612); Josef 
de, dass Ulrich Desiderius Pruskowsky von Pruskau eilig den Priester Georg aus dem St.Veits-Dom holen ließ, damit der Kaiser die Beichte ablegen und die Kommunion und die Letzte Ölung empfangen könne, zweifelten einige Zeitgenossen daran, ob der Kaiser tatsächlich als tiefgläubiger Katholik hingeschieden war ${ }^{99}$. Das hing vielleicht damit zusammen, dass einige Gesandte behaupteten, dass der Kaiser die Beichte zwar abgelegt, der plötzliche Tod aber den Empfang der Kommunion verhindert hätte ${ }^{100}$. Zweifel riefen auch Berichte über die Anwesenheit des Leibdieners Hans Marckher hervor ${ }^{101}$, der dem Herrscher angeblich ein weißes Hemd hätte bringen sollen, das Rudolf II. unmittelbar vor seinem Tod selbst angezogen hätte ${ }^{102}$. Auf der Apenninen- und Pyrenäenhalbinsel langten aus Prag diplomatische Berichte ein, die nachdrücklich festhielten, dass der Kaiser nicht nur eine ordentliche Beichte bei klarem Verstand abgelegt, sondern auch seinem Bruder Matthias alles Unrecht verziehen hatte ${ }^{103}$. In diesen Textzeugnissen spiegelt sich das erwartbare Bild vom Ritual des guten Todes des Kaisers, der die feste Grundlage für sein Leben nach dem Tod schuf, wider.

Oberstkämmerer Ulrich Desiderius Pruskowsky von Pruskau, der die Verantwortung für die alltägliche Pflege des Kaisers, für seine Gemächer und für die Gegenstände des persönlichen Bedarfs trug, sah vermutlich als Erster den Leichnam des Kaisers ${ }^{104}$. Da der Oberstkämmerer in seinem Palais in der Loreto-Straße auf dem Hradschin wohnte ${ }^{105}$, hatte er es zu den Gemächern Rudolfs II. auf der Prager Burg nicht weit. Zusammen mit dem Oberstkammerdiener durfte er nicht nur das Schlafzimmer des Kaisers betreten, sondern er kannte die Bekleidung, die Juwelen und die Gegenstände,

Vítězslav ŠımáK, Paměti Vodňanských z Uračova [Die Memoiren Vodňandskýs von Uračov]. Časopis Společnosti prátel starožitností českých 10 (1902) 10-15, 53-59, hier 54; Příběhy Jindřicha Hýzrla z Chodů [Die Geschichten Heinrichs Hieserle von Chody], hg. von Věra PetráčKová-Jan Vogeltanz (Praha 1979) 283; Chroust (Bearb.), Briefe und Akten (wie Anm. 91) 241f.; Heinz Schlecker, Das Prager Tagebuch des Melchior Goldast von Haiminsfeld in der Bremer Staatsbibliothek. Abhandlungen und Vorträge der Bremer Wissenschaftlichen Gesellschaft 5 (1930) 258-272, hier 262 - dazu die tschechische Übersetzung von PÁnek, Když císař odchází (wie Anm. 22) 15-17; Vocelka, Die politische Propaganda (wie Anm. 3) 324; DERs., Rudolf II. und seine Zeit (wie Anm. 1) 212; JANÁČEK, Rudolf II. a jeho doba (wie Anm. 1) 503f.; Hilda Lietzmann, Herzog Heinrich Julius zu Braunschweig und Lüneburg (1564-1613). Persönlichkeit und Wirken für Kaiser und Reich (Quellen und Forschungen zur Braunschweigischen Geschichte 30, Braunschweig 1993) 69f.; Deník rudolfínského dvořana. Adam mladší z Valdštejna 1602-1633 [Das Tagebuch des Rudolfinischen Hofmannes. Adam der Jüngere von Waldstein 1602-1633], hg. von Marie Koldinská-Petr Mat’a (Praha 1997) 191.

99 Hosmann, Lacrymae (wie Anm. 98); Schlecker, Das Prager Tagebuch (wie Anm. 98) 262f.; JANÁČEK, Rudolf II. a jeho doba (wie Anm. 1) 503; PÁNEK, Když císař odchází (wie Anm. 22) 15f.; Pavel KRÁL, Smrt a pohřby české šlechty na počátku novověku [Der Tod und Begräbnisse des böhmischen Adels zu Beginn der Neuzeit] (Monographia historica 4, České Budějovice 2004) 122-128.

100 NA, SO, CA - Vatikán, Ř́m, Itálie, Kart. 223 (Tomasso Roncaroli an Ranuccio Farnese, Herzog von Parma und Piacenza, Prag, 23.1.1612).

101 Der ehemalige Kammerheizer gehörte seit 1611 zu den Kammerdienern. Dazu Der Hof Kaiser Rudolfs II. (wie Anm. 7) 359, 402, 410.

102 Hosmann, Lacrymae (wie Anm. 98); Schlecker, Das Prager Tagebuch (wie Anm. 98) 262f.; JANÁČEK, Rudolf II. a jeho doba (wie Anm. 1) 503; PÁNEK, Když císař odchází (wie Anm. 22) $15 f$.

103 ASMa, L'archivio dei Gonzaga di Castiglione delle Stiviere, busta 246 (Rodolfo Petrocini an Francesco Gonzaga di Castiglione, Prag, 21.1.1612); NA, Gindelyho sbírka [Gindelys Sammlung], Kart. 4, Heft 21 (Avisos de Praga, 21. 1. 1612). Vgl. Hosmann, Lacrymae (wie Anm. 98).

${ }_{104}$ Der Hof Kaiser Rudolfs II. (wie Anm. 7) 94-98.

105 Václav Ledvinka-Bohumír Mráz-Vít Vlnas, Pražské paláce (Encyklopedický ilustrovaný přehled) [Prager Paläste (Enzyklopädischer illustrierter Überblick)] (Praha 1995) $138 f$. 
mit denen sich Rudolf II. umgab, weil er für deren tadellosen Zustand zuständig war. Diesen Tätigkeitsbereich nutzte Ulrich Desiderius Pruskowsky auch, um seinen unmittelbaren Einfluss auf den Herrscher zu stärken. Der Oberstkämmerer versuchte, die Nachricht vom Tod des Kaisers zu verheimlichen, bis zuerst Matthias in Wien verständigt war, und befahl deshalb den Dienern, den Tisch zum Mittagessen nach der üblichen Gewohnheit auch für den verstorbenen Rudolf II. zu decken ${ }^{106}$.

Schon um zehn Uhr am Vormittag sahen auch Wilhelm Wchynsky von Wchynitz und Adam von Trauttmansdorff den Leichnam und verbreiteten die Nachricht rasch in der Prager Burg ${ }^{107}$. Sie waren dafür verantwortlich, dass noch am Vormittag nicht nur die Geheimräte Heinrich Julius von Braunschweig und Georg Ludwig von Leuchtenberg davon erfuhren, sondern dass auch Joachim Ernst von Brandenburg-Ansbach und Christian I. von Anhalt-Bernburg, die in Prag weilten, diese Nachricht erhielten ${ }^{108}$. Johann Martin Rebmann, Agent des Erzbischofs von Mainz Johann Schweikhard von Kronberg, blieb nicht verborgen, dass sich unmittelbar nach dem Tod des Kaisers Joachim Ernst von Brandenburg-Ansbach und Johann Anton Barvitius in aller Eile trafen, um im Hinblick auf die geplante Wahl von Matthias zum Kaiser über das Verhältnis zwischen den konfessionellen und politischen Kräften im Heiligen Römischen Reich zu beraten ${ }^{109}$.

Unmittelbar nach dem Tod Rudolfs II. versiegelten Ulrich Desiderius Pruskowsky von Pruskau und Adam von Trauttmansdorff mit rotem und weißem Wachs die Tür zu den privaten Gemächern des Herrschers, seine Wertgegenstände, die offiziellen Dokumente und eine kleinere Menge an Bargeld ${ }^{110}$. Einen Teil der Juwelen brachte noch vor dem Tod des Kaisers wahrscheinlich sein Oberstkammerdiener Kaspar Rucky an sich $^{111}$. Er und Daniel Fröschl wurden zusammen mit den anderen Hofbediensteten, die Zutritt zu den wertvollen Gegenständen des Kaisers hatten, nach dem Tod des Herrschers auf Befehl Adams von Trauttmansdorff ins Gefängnis geworfen, wo Rucky am 10. Februar 1612 tot aufgefunden wurde. Nach offizieller Ansicht hatte er Selbstmord durch Erhängen mit eben dem Seil begangen, an dem der Schlüssel zu den Gemächern des Kaisers hing ${ }^{112}$. Auch wenn sich die Neuigkeit vom Selbstmord Kaspar Ruckys

106 Hosmann, Lacrymae (wie Anm. 98); Schlecker, Das Prager Tagebuch (wie Anm. 98) 262f.; JANÁČEK, Rudolf II. a jeho doba (wie Anm. 1) 503; PÁNEK, Když císař odchází (wie Anm. 22) $15 f$.

107 Adam von Trauttmansdorff war Hofkriegsrat, Hauptmann der Hartschiere, und einstweilig gehörte er zu den Kämmerern. Dazu Der Hof Kaiser Rudolfs II. (wie Anm. 7) 223, 323, 398. Wilhelm Wchynsky von Wchynitz war seit 1611 Oberstjägermeister des Königreichs Böhmen. Vgl. Václav LívA, Spiknutí Vchynských proti Rudolfovi II. [Die Verschwörung Wchynskys von Wchynitz gegen Rudolf II.]. Věstník Královské české společnosti nauk, trída filosoficko-historicko-filologická (Praha 1928) 1-56. Über die Rolle, die beide Adeligen nach dem Tod des Kaisers spielten, berichtet der Brief Rodolfo Petrocinis an Francesco Gonzaga di Castiglione delle Stiviere (Prag, 21.1.1612) - ASMa, L'archivio dei Gonzaga di Castiglione delle Stiviere, busta 246, Rodolfo Petrocini (1611-1616).

108 Hosmann, Lacrymae (wie Anm. 98); Lietzmann, Herzog Heinrich Julius (wie Anm. 98) 69; Deník (wie Anm. 98) 191f.; Der Hof Kaiser Rudolfs II. (wie Anm. 7) 204.

109 Chroust (Bearb.), Briefe und Akten (wie Anm. 91) $241 \mathrm{f}$.

110 Giovanni Battista Salvago wunderte sich in einem Brief an Kardinal Scipio Caffarelli-Borghese (Prag, 9.3. 1612), dass außer den merkwürdigen Wertsachen in den Gemächern des verstorbenen Kaisers nur eine sehr geringe Geldmenge zu finden war; dazu NA, SO, CA - Vatikán, Ř́m, Itálie, Kart. 109.

111 Herzog August Bibliothek Wolfenbüttel, H : L 996. $4^{0}$ Helmst. (21); Hosmann, Lacrymae (wie Anm. 98); Deník (wie Anm. 98) 192, 366; PÁnek, Když císař odchází (wie Anm. 22) 23.

112 ASMa, L'archivio dei Gonzaga di Castiglione delle Stiviere, busta 246, Rodolfo Petrocini 16111616 (Rodolfo Petrocini an Francesco Gonzaga di Castiglione delle Stiviere, Prag, 21.1.1612); NA, SO, 
schnell verbreitete, zweifelten Personen aus dem Kreis des gut informierten päpstlichen Nuntius daran; sie vermuteten, dass der ehemalige Oberstkammerdiener in Wirklichkeit ermordet worden war ${ }^{113}$. Obwohl das sichergestellte Bargeld und die Juwelen Kaspar Ruckys Matthias zukamen, bemühte sich die Witwe darum, einen Teil des Vermögens des Oberstkammerdieners, dessen Körper auf dem Schafott geviertelt und dem danach das Haupt abgetrennt und das Herz entnommen wurden, zurückzuerhalten ${ }^{114}$.

Sobald die Geheimräte die Nachricht von Rudolfs Tod erhalten hatten, ließen sie Briefe mit der kurzen Todesnachricht verfassen ${ }^{115}$. Nach zehn Uhr entsandten sie den Kämmerer Joachim Metych von Tschetschow mit einem Brief für Matthias nach Wien ${ }^{116}$. Auch Heinrich Julius von Braunschweig sandte einen eigenen Boten mit der Todesmeldung unverzüglich in die Wiener Hofburg ${ }^{117}$. In den Nachmittags- und Abendstunden des 20. Jänner 1612 verließen auch Eilboten an die Höfe der beiden anderen lebenden Brüder Rudolfs II. Prag. Ihre Reise führte nach Brüssel zu Erzherzog Albrecht und nach Innsbruck zu Erzherzog Maximilian. Baltasar Zúñiga schickte die Todesnachricht nach Madrid und nach Brüssel ${ }^{118}$. Ein Kurier wurde auch nach Graz abgesandt, wo Rudolfs Cousin Erzherzog Ferdinand residierte, doch widmeten die Geheimen Räte Rudolfs mehr Aufmerksamkeit vor allem jenen Briefen, welche die Boten in die Residenzen der Kurfürsten, des ungarischen Palatins Georg Thurzo und in die Residenzen auf der Appeninenhalbinsel überbringen sollten ${ }^{119}$.

Die meisten Todesmeldungen nach Madrid, Mantua, Rom und in die weiteren politischen Zentren des katholischen Europas verließen Prag aber erst am nächsten Tag ${ }^{120}$. Die Ursachen der Verzögerung lagen weniger in der Lässigkeit der Gesandten, sondern waren ökonomisch begründet. Eine Entsendung eines Kuriers in entfernte Gebiete war finanziell sehr aufwändig, daher entschied sich Baltasar Zúniga zusammen mit den meisten Gesandten aus der Appeninenhalbinsel mit dem Versand der Todesmeldung zuzuwarten, bis er die Informationen über den Verlauf der Obduktion erhalten hatte ${ }^{121}$. Die Todesnachricht wurde in Prag und in vielen Reichsstädten mit dem Geläut der Kirchenglocken, mit dem Verhängen der Kanzeln mit schwarzem Tuch (mit kaiserlichen

CA - Vatikán, Ř́m, Itálie, Kart. 223 (Tomasso Roncaroli an Ranuccio Farnese, Herzog von Parma und Piacenza, Prag, 13.2.1612); Deník (wie Anm. 98) 192, 366.

113 Real Academia de la Historia Madrid, Colección jesuitas, tomo 89, fol. 180-181 (por carta de Roma de 28 de marzo de 1612).

114 Siehe Anm. 112.

115 HHStA, FA, Kart. 65.

116 Chroust (Bearb.), Briefe und Akten (wie Anm. 91) 242-248; NA, Stará manipulace [Alte Manipulation], Sign. K-1, Inv. Nr. 1580, Kart. 1053 (die höchsten böhmischen Landesbeamten an Matthias, 31.1. 1612); Der Hof Kaiser Rudolfs II. (wie Anm. 7) 397.

117 Lietzmann, Herzog Heinrich Julius (wie Anm. 98) 69.

118 Chroust (Bearb.), Briefe und Akten (wie Anm. 91) 242-248.

119 HHStA, FA, Kart. 65.

120 ASMa, L'archivio dei Gonzaga di Castiglione delle Stiviere, busta 246 (Rodolfo Petrocini an Francesco Gonzaga di Castiglione, Prag, 21.1.1612); NA, Gindelyho sbírka [Gindelys Sammlung], Kart. 4, Heft 21 (Avisos de Praga, 21.1.1612).

${ }^{121}$ Josef BorovičKA, Archiv v Simancasu - př́spěvek ke kritice zpráv španělských vyslanců [Archiv in Simancas - ein Beitrag zur Kritik der Nachrichten von spanischen Botschaftern]. Zprávy Zemského archivu Království českého 3 (1910) 115-180; Miroslav PoLišEnskŕ, Las Relaciones Postales BohémicoEspañolas en la Época anterior a la Montaña Blanca 1516-1612. Ibero-americana Pragensia 17 (1983) 233-249. 
Symbolen), mit der Abhaltung von Trauergottesdiensten und mit der Einstellung aller lauten Lustbarkeiten auf den Straßen begangen ${ }^{122}$.

In den Nachmittagsstunden des 20. Jänner 1612 fand unter der Aufsicht Ottavio Roboretos und Simon Pergers die Obduktion des Leichnams Rudolfs II. statt. Dem sechs Tage später verfassten Obduktionsbericht zufolge waren bei dieser Obduktion nur der Oberstkämmerer Ulrich Desiderus Pruskowsky von Pruskau, der Reichshofrat Johann Anton Barvitius, die Kämmerer Johann Nowohradsky von Kolowrat und Ferdinand Casteletti von Nomi zugegen ${ }^{123}$. Obwohl sich eine Teilnahme der Geheimräte Heinrich Julius von Braunschweig und Georg Ludwig von Leuchtenberg nicht ausschließen lässt, scheinen sie im Obduktionsbericht nicht auf ${ }^{124}$. Überraschend für die Ärzte war der ungewöhnlich kleine, mit Flüssigkeit gefüllte Herzbeutel, in dem das große Herz Rudolfs II. eingebettet war. Größere Beachtung verdient der Befund von kaum sichtbaren Narben auf den Herzkammern, die darauf hindeuten, dass der Kaiser einen Infarkt des Herzmuskels erlitten hatte. Die schwarz gefärbte Lunge des Verstorbenen beinhaltete Blutklumpen. In der gehärteten Leber sammelte sich die Gallflüssigkeit, die an der Oberfläche Entzündungsherde bildete. Die geöffneten Wunden an den beiden Beinen und Füßen des Kaisers waren mit Gangrän befallen. Der Inhalt des Obduktionsberichts lässt vermuten, dass die fortgeschrittene ansteckende Erkrankung, vermutlich Syphilis, nicht die alleinige Todesursache war; eine Erkrankung der Atemwege und des Verdauungsapparats hatte sich negativ auf den Gesundheitszustand Rudolfs ausgewirkt und das kranke Herz das Ende des Kaisers beschleunigt ${ }^{125}$.

Höchstwahrscheinlich am Tag der Obduktion schritt man auch zur Einbalsamierung des Leichnams des verstorbenen Kaisers. Zur Konservierung der menschlichen Überreste bediente man sich zu Beginn des 17. Jahrhunderts gewöhnlich zweier Verfahren. Das erste Verfahren, das die übergangsweise Erhaltung des Leichnams über den Zeitraum seiner Ausstellung sicherstellen sollte, bestand im Ausfüllen des Körpers mit wohlriechenden Lösungen und im Verstopfen der Mund-, Ohren- und Nasenhöhlen. Die zweite Konservierungsmethode, die dagegen bei der Einbalsamierung der Leiche Rudolfs II. Anwendung fand, erforderte die Öffnungen des Kopfes und der Brustund Bauchhöhle. Die Barbiere entfernten das Herz und alle inneren Organe, die in eigenen Behältern getrennt bestattet wurden. Die restlichen Muskeln im Körper wurden angeschnitten und getrocknet. Die Körperhöhlen wurden gründlich gewaschen und mit wohlriechendem Gewürz, Kalk und Salz gefüllt. Nach dem Ausfüllen der Körperhöhlen wurden die Schnittwunden vernäht und der Leichnam mit Binden fest umwickelt. Die größte Aufmerksamkeit galt bei der Einbalsamierung dem Gesicht, das im Gegensatz zum restlichen Körper nicht verhüllt wurde. Mit der Anwendung von Salben

\footnotetext{
122 Hosmann, Lacrymae (wie Anm. 98).

${ }^{123}$ HHStA, FA, Kart. 65; Der Hof Kaiser Rudolfs II. (wie Anm. 7) 212, 394, $396 f$.

124 Vgl. Lietzmann, Herzog Heinrich Julius (wie Anm. 98) 69. Die Beschreibung der Obduktion nach JANÁČEK, Rudolf II. a jeho doba (wie Anm. 1) 504, der sich nur auf das Zeugnis Pavel Skálas von Zhoř stützte, halten die Autoren der Studie mit der Kenntnis des überlieferten Obduktionsberichtes für kaum wahrscheinlich. Dazu Pavla Skály ze Zhoře Historie česká od roku 1602 do roku 1623.1 (16021616) [Pavel Skálas von Zhoř Böhmische Geschichte seit dem Jahr 1602 bis zum Jahr 1623. 1 (16021616)], hg. von Karel Tieftrunk (Praha 1865) $330 \mathrm{f.}$

${ }_{125}$ HHStA, FA, Kart. 65. Für genauere Übersetzung der lateinischen medizinischen Termini bedanken sich die Autoren bei Bohdana Divišová.
} 
und Wachs bemühten sich die Barbiere, sein früheres, natürliches Aussehen wieder herzustellen ${ }^{126}$.

Herz und Gehirn Rudolfs II. wurden nach ihrer Entnahme in zwei vergoldete und mit Grünspan versehene, silberne Behälter gelegt, die gemeinsam mit dem Leichnam des Kaisers in einem Sarg bestattet wurden ${ }^{127}$. Das Herz betrachtete man zu Beginn der Neuzeit als das wichtigste Organ im menschlichen Körper, aus dem der Quell des Lebens - das Blut - entsprang. Nach zeitgenössischer Vorstellung bildete sich das Herz vor allen anderen Organen im menschlichen Körper und starb auch zuletzt. Der Aufgabe des Herzens im menschlichen Körper entsprach die Rolle des Königs in der Gesellschaft. Ähnlich wie das Herz den Mittelpunkt des Körpers bildete und diesen am Leben erhielt, stand auch der König im Zentrum der menschlichen Gesellschaft und gewährleistete deren Existenz ${ }^{128}$. Die Bestattung des Gehirns Rudolfs II. in einem selbstständigen Behälter ging über die üblichen Gepflogenheiten hinaus und lässt sich nicht mit anderen Begräbnissen nach der habsburgischen Tradition vergleichen. Die entfernten Eingeweide (intestina) wurden in Leinwand gewickelt und in einen Schrein aus Ebenholz, der mit Eisenblech beschlagen war, gegeben. Der Oberstkämmerer Ulrich Desiderius Pruskowsky von Pruskau und der Oberststallmeister Maximilian von Salm trugen ihn gemeinsam mit den obersten Landesbeamten des Königreichs Böhmen und einigen Leibkämmerern in die Sächsische Kapelle im St.-Veits-Dom, wo sie ohne pompöse Zeremonien am Abend des 21. Jänner 1612 beigesetzt wurden ${ }^{129}$. Die teure und aufwändige Einbalsamierung des Leichnams stellte eine Voraussetzung für die nachfolgende Aufbahrung des Verstorbenen dar, gleichzeitig handelte es sich um ein wichtiges distinktives Element, das die Exklusivität und Dignität der Eliten zur Geltung brachte. Der einbalsamierte Leichnam versinnbildlichte die bleibende Memoria an den verstorbenen Monarchen und an seine außergewöhnlichen Qualitäten. Daran konnten auch die deutlichen Zeichen des Verfalls, die selbst die Einbalsamierung nicht aufhalten konnte, nichts ändern ${ }^{130}$.

Nach der Obduktion, der Einbalsamierung und der Bekleidung wurde der Leichnam Rudolfs II. vom 21. Jänner bis zum 5. Februar 1612 im Audienzsaal, im zweiten Geschoß des südlichen Flügels der Prager Burg, öffentlich aufgebahrt. Die ungewöhnlich lange Zeit der Verabschiedung war durch das frostige Winterwetter und die hervorragend durchgeführte Einbalsamierung beeinflusst. Die Wahl des Audienzsaals für die Ausstellung des Leichnams war nicht zufällig getroffen, weil sich darin der Stuhl befand, auf dem der Kaiser saß, wenn er den Worten der auswärtigen Gesandten zuhörte. Nun verwandelte sich der Raum in die imaginäre Bühne einer Trauerperforman-

126 Dazu mehr Robert G. MaYer, Embalming: History, Theory and Practice (New York 2005).

127 Milena Bravermanová-Michal LutovskÝ, Hroby, hrobky a pohřebiště českých knížat a králů [Grabstätten, Grüfte und Begräbnisstätten der böhmischen Fürsten und Könige] (Praha 2001) 239-241. Abraham Hosmann führt irrtümlich an, dass das Herz zusammen mit dem Gehirn des Kaisers nach Spanien geschickt wurde. Dazu Hosmann, Lacrymae (wie Anm. 98); ähnlich Vocelka, Die politische Propaganda (wie Anm. 3) 328.

128 Javier VARELA, La muerte del Rey. El ceremonial funerario de la Monarquia Española (15001885) (Madrid 1990) $79 f$.

129 Deník (wie Anm. 98) 191, 366. Neben den erwähnten Hofwürdenträgern beteiligten sich an der Überführung Adam der Jüngere von Waldstein, Johann Nowohradsky von Kolowrat und Johann Rudolf Trčka von Leipa; Hosmann, Lacrymae (wie Anm. 98); Vocelka, Die politische Propaganda (wie Anm. 3) 328.

130 Varela, La muerte (wie Anm. 128) 80f. 
ce, in welcher der Leichnam des Kaisers, aufgebahrt auf dem mit Baldachin überzogenen Paradebett, die Hauptrolle spielte. An den Wänden des Raumes standen Altäre, an denen immer wieder Geistliche für das Seelenheil Rudolfs II. beteten ${ }^{131}$. Die Gelegenheit, den Kaiser, der sich jahrelang vor den Blicken verborgen hatte, mit eigenen Augen zu sehen, ließen sich große Menschenmengen nicht entgehen. Viele der Besucher wollten sich wenigstens flüchtig dem wundertätigen und geheiligten Königtum nähern, das der Leichnam des Monarchen ausstrahlte. Der Glaube an das übernatürliche Vermögen des Herrscherkörpers war für die Gläubigen des 17. Jahrhunderts noch präsent ${ }^{132}$.

Die Überlieferungen bezüglich der Kleidung, die der Leichnam des verstorbenen Kaisers trug, differieren stark. Die erhaltenen bildnerischen Darstellungen des Paradebetts Rudolfs II. zeigen den Kaiser in einem langen dunklen Mantel mit einem Hut auf dem Kopf. Der Gesandte des Markgrafen Gonzaga di Castiglione Rodolfo Petrocini schrieb nach der Teilnahme an der Trauermesse vom 24. Jänner 1612 im Audienzsaal, dass der Leichnam in ein Gewand von silbernem Atlasstoff gekleidet war. Einen Monat später berichtete auch der sächsische Gesandte Melchior Goldast von einem derartigen Mantel. Nach seiner Darstellung handelte es sich um dunkelgoldene Farbe. An der Trauerkleidung des Kaisers fielen ihm das Barett aus Samt auf dem Kopf, der Mantel, die Hose und der schwarze Ringkragen mit dem Agnus Dei (schwarzes Binden, daran hengt ein Agnes Dei) auf, das an das Opfer Jesu Christi erinnerte ${ }^{133}$.

Als im Jahr 1928 der Sarg mit den Überresten Rudolfs II. erstmals geöffnet wurde, stellte man fest, dass sein Leichnam in einen dunkelgoldenen Mantel mit zierlichen Pflanzenmotiven gewickelt war. Der Verstorbene trug weit geschnittene Kniehosen aus dem gleichen Stoff wie sein Mantel. An den Beinen konnte man Strümpfe und Pantoffeln aus Samt mit einer Korksohle sehen. Den Kopf schmückte ein hoher, schmalkrempiger Hut. Seine Hände mit drei Ringen hielten ein hölzernes Kruzifix. Zur Trauerausstattung gehörten der Rosenkranz und zwei viszerale Behälter mit dem Herz und dem Gehirn des Verstorbenen. Die divergierenden Zeugnisse Rodolfo Petrocinis und Melchior Goldasts, die wiederum vom Befund der erhaltenen Trauerausstattung abweichen, führen zur Annahme, dass der Leichnam des Herrschers während der Exequien wahrscheinlich mehrmals umgezogen wurde ${ }^{134}$.

Die öffentliche Exposition der körperlichen Überreste des verstorbenen Kaisers stellte den ersten Schritt des katholischen Bestattungsrituals dar, mit dem das Hinscheiden des biologischen Herrscherkörpers von der irdischen Welt im kollektiven Gedächtnis durch die Unsterblichkeit des sozialen Körpers ersetzt wurde ${ }^{135}$. Die brennenden Ker-

131 ASMa, L'archivio dei Gonzaga di Castiglione delle Stiviere, busta 246, Rodolfo Petrocini 16111616 (Rodolfo Petrocini an Francesco Gonzaga di Castiglione delle Stiviere, Prag, 24. 1. 1612); Archivio di Stato di Torino, Lettere ministri, Austria, mazzo 6, Praga 1601-1607 (Gieronimo Lovencito an Karl Emanuel nach Torino, Regensburg, 10.4.1612).

132 Marc Bloch, Králové divotvůrci. Studie o nadpřirozenosti přisuzované královské moci, zejména ve Francii a Anglii [Die wundertätigen Könige. Eine Studie über die königliche Macht und die königliche Magie, besonders in Frankreich und England] (Praha 2004) 199-205.

133 Dazu Hosmann, Lacrymae (wie Anm. 98); vgl. Kupferstich aus dem Kreis Aegidius Sadelers, veröffentlicht bei Vocelka, Rudolf II. und seine Zeit (wie Anm. 1) 213; Lietzmann, Herzog Heinrich Julius (wie Anm. 98) 70; Milena Bravermanová, Pohřební výbava Rudolfa II. [Die Ausstattung des Begräbnisses von Rudolf II.], in: Rudolf II. a Praha (wie Anm. 1) 284-287, hier 287.

134 Vgl. JANÁČEK, Rudolf II. a jeho doba (wie Anm. 1) 505.

135 Kantorowitz, The King's Two Bodies (wie Anm. 22); zusammenfassend KráL, Smrt a pohřby (wie Anm. 99) 122-128, 171-175. 
zen, mit denen der Leichnam des Kaisers umgeben war, schützten den Verstorbenen nicht nur vor den teuflischen Kräften, sondern sie zeigten der Seele den Weg zum ewigen Heil. Das Gesicht des Herrschers war dem Kruzifix zugewandt, das daran erinnerte, dass Jesus Christus durch seinen Tod die Sünden der Gerechten erkauft hatte. Neben dem Kopf lagen der Orden vom Goldenen Vlies und das Schwert - Symbole der Herrschaft eines christlichen Ritters, der standhaft im katholischen Glauben war. Beim aufgebahrten Leichnam hielten die Leibkämmerer Wacht, daneben wirkten Kapläne und Musi$\operatorname{ker}^{136}$. Zur Verscheuchung der Dämonen und zur Reinigung des Aufbahrungsraumes dienten das Weihwasser und der Weihrauch, der in die Nähe des Kruzifixes brannte. Unter den Trauernden, die bis zum 5. Februar 1612 kamen, um vom biologischen Körper Rudolfs II. Abschied zu nehmen, kam Heinrich Julius von Braunschweig, der sich nach dem Zeugnis des Gesandten Rodolfo Petrocini mit dem Tod des Kaiser nicht abfinden konnte ${ }^{137}$, eine privilegierte Stellung zu.

Sobald Matthias am 24. Jänner 1612 vom Tod seines älteren Bruders Rudolf II. benachrichtigt worden war, brach er unverzüglich mit seiner Gemahlin Anna und seinen Höflingen von Wien nach Prag auf, wo er sechs Tage später eintraf ${ }^{138}$. Obwohl er sich in der Hauptstadt des Königreichs Böhmen mit den obersten Landesbeamten traf, hörte er besonders auf die Ratschläge von Heinrich Julius von Braunschweig, der das Königspaar am 20. Februar in seinem noch nicht ganz fertig gebauten Palais in der Loreto-Straße auf dem Hradschin beherbergte ${ }^{139}$. Erst einen Monat nach dem Tod Rudolfs II. begannen die nächsten Familienmitglieder mit der Vorbereitung des Abschieds vom verstorbenen Kaiser. Aus Prag wurden Briefe nach Brüssel, Innsbruck und Graz abgesandt, die einige Fragen von grundsätzlicher Bedeutung beinhalteten. Matthias wartete auf Antworten nicht nur von den jüngeren Brüdern Albrecht und Maximilian, sondern auch von seinem Cousin Ferdinand ${ }^{140}$. Der König von Böhmen wollte vor allem wissen, wo der Leichnam vor dem Begräbnis aufbewahrt werden sollte; weiters waren ihm die Publikation der Landestrauer und die Namen derjenigen Personen, die die Trauerkleidung anlegen sollten, wichtig. Von den Verwandten verlangte Matthias Antworten auf die Fragen bezüglich der Hofgröße, der Bezahlung der Löhne für die Dienerschaft und der Bezahlung von Rudolfs Schulden. Dem schüchternen Nachfolger war nicht klar, ob er den alten Hof bis zum Begräbnis seines Bruder behalten musste oder nicht. Den ausländischen Gesandten fiel der große Einfluss auf, den neben Johann Anton Barvitius der Geheime Rat Ernst von Mollart in den Tagen des Überganges ausübte (protectores und directores der kaiserlichen verlassenen hofstadt) ${ }^{141}$.

136 NA, SO, CA - Vatikán, Ř́m, Itálie, Kart. 223 (Tomasso Roncaroli an Ranuccio Farnese, Herzog von Parma und Piacenza, Prag, 23.1.1612).

137 Lietzmann, Herzog Heinrich Julius (wie Anm. 98) 70; Rodolfo Petrocini an Francesco Gonzaga di Castiglione delle Stiviere (Prag, 21. 1. 1612). Dazu auch ASMa, L'archivio dei Gonzaga di Castiglione delle Stiviere, busta 246, Rodolfo Petrocini 1611-1616.

${ }^{138}$ HHStA, FA, Kart. 65; JanÁČek, Rudolf II. a jeho doba (wie Anm. 1) 504; Deník (wie Anm. 98) 192.

139 Deník (wie Anm. 98) 192; Hosmann, Lacrymae (wie Anm. 98).

140 HHStA, FA, Kart. 65; Vocelka, Die politische Propaganda (wie Anm. 3) 325.

${ }_{141}$ Herzog August Bibliothek Wolfenbüttel, H : L 996. $4^{0}$ Helmst. (21); Der Hof Kaiser Rudolfs II. (wie Anm. 7) 206, 212; Felix Stieve, Mollart Ernst. ADB 22 (1885) 117f.; Archivio di Stato di Torino, Lettere ministri, Austria, mazzo 6, Praga 1601-1617 (Gieronimo Lovencito an Karl Emanuel nach Torino, Regensburg, 10.4. 1612). 
Im entfernten Madrid erhielt man die traurige Nachricht vom Tod Rudolfs II., die durch den vom Prager Nuntius entsandten Kurier überbracht wurde, am 1. Februar $1612^{142}$. Die knapp formulierte Todesbekundung beinhaltete neben den Angaben zum Tod des Kaisers die Ergebnisse der Obduktion, die Schätzung des nachgelassenen Vermögens und Informationen über jene Höflinge, die Zutritt zu den Wertsachen des verstorbenen Herrschers hatten. Der Bericht erwähnt insbesondere die Resultate der Obduktion, die gehärtete Leber des Kaisers, seine angegriffene Lunge, sein weißliches Herz, die schwarz verfärbte Haut an den Oberschenkeln und die vermehrte Flüssigkeit im Gehirn. Da niemand aus der Prager Nuntiatur Zugang zum Obduktionsbericht, den die Hofärzte erst am 26. Jänner 1612 verfasst hatten, haben konnte, liegt die Vermutung nahe, dass der Nuntius oder eine ihm nahestehende Person entweder selbst an der Obduktion teilnahm oder genaue Informationen durch einen Anwesenden erhielt. Der Inhalt des nach Madrid gesandten Berichtes korrespondierte auffallend mit dem schriftlichen Obduktionsbericht ${ }^{143}$. Während jedoch die Angaben über den Zustand der körperlichen Überreste Rudolfs im Madrider Bericht im Wortlaut mit anderen zeitgenössischen Zeugnissen übereinstimmen, unterschieden sich die Berichte überraschenderweise beim Todeszeitpunkt. Der Autor verlegte den Moment des letzten kaiserlichen Atemzugs von den Morgenstunden auf elf Uhr vormittags. Die Ursache dieser Differenz könnte in den unterschiedlichen Modalitäten der Zeitmessung begründet liegen, da die Stundenmessung von einem Sonnenuntergang bis zum nächsten verlief und damit nicht, wie heute üblich, mit Mitternacht endete ${ }^{144}$.

Der Autor des Berichtes erwähnte auch die öffentliche Aufbahrung des Leichnams des Kaisers, den nun alle sehen konnten, vor denen sich der Monarch zu Lebzeiten angeblich im Labyrinth der Gänge und Gemächer der Prager Burg verborgen hatte. Rudolf II. besaß in den Augen der Bewohner der Pyrenäenhalbinsel genauso wie der spanische König die Gestalt eines unsichtbaren Königs (rey invisible) ${ }^{145}$. Ein derartiger Vergleich lag nahe, weil sich alle Biographen Rudolfs II. über die große Bedeutung des langjährigen Aufenthalts des künftigen Kaisers am spanischen Hof einig sind ${ }^{146}$. Als wichtiges Ergebnis der spanischen Erziehung gilt die Tatsache, dass Rudolf die persönliche Teilnahme am öffentlichen Leben - der Auffassung Philipps II. entsprechend aufs Äußerste einschränkte. Gerade die „Unsichtbarkeit“ des Kaisers, die nur ausnahmsweise bei öffentlichen Zeremonien aufgehoben wurde, sollte das Außenbild des abstrakten, gleichzeitig jedoch allgegenwärtigen, geheiligten und unsterblichen Monarchen verkörpern. Die Absenz Rudolfs II. vom öffentlichen Leben führte auch zur unbestätigten Annahme, dass der Kaiser seine Umgebung aus einem Versteck hinter den Vorhängen beobachtete, durch die geheimen Gänge der Prager Burg spazierte und seine Untertanen überall kontrollierte. Sogar enge Vertraute konnten sich nicht sicher sein, ob Rudolf sie

\footnotetext{
142 Real Academia de la Historia Madrid, Colección jesuitas, tomo 105, fol. 245-246 (Relación de la muerte del Emperador); ebd., tomo 88, fol. 331 (Relación de la muerte del Emperador en Praga).

143 Ebd.

144 Josef EmLer, Rukovět chronologie křestanské, zvláště české [Handbuch der christlichen Chronologie, besonders der tschechischen] (Praha 1876) 26.

145 María José Del Río Barredo, Madrid. Urbs Regia. La capital ceremonial de la Monarquía Católica (Madrid 2000) 44-54.

146 Zum Aufenthalt Rudolfs II. in Spanien vgl. Erwin MaYer-Löwenswerdt, Der Aufenthalt der Erzherzoge Rudolf und Ernst in Spanien 1564-1571 (Wien 1927).
} 
nicht gerade im Visier hatte ${ }^{147}$. Nach Rudolfs Tod wurden die erwähnten Machtattribute des „unsichtbaren“ Monarchen im kollektiven Gedächtnis auf seinen sozialen Körper übertragen $^{148}$.

Rudolfs Leichnam wurde um drei Uhr in der Nacht vom 5. auf den 6. Februar 1612 in Gegenwart Heinrichs Julius von Braunschweig über den Wladislawschen Saal in die Allerheiligenkirche der Prager Burg überführt, wo er vorübergehend bei offenem Sarg ausgestellt wurde ${ }^{149}$. Nach dem Zeugnis des sächsischen Gesandten Melchior Goldasts, der mit der Erlaubnis von Matthias am 24. Februar die Überreste des Verstorbenen sah, kam es zu einer schnellen Zersetzung des Gewebes. Da der Leichnam des Monarchen ganz bedeckt war, fiel dem sächsischen Gesandten nur die fortschreitende Verwesung des Gesichtes auf ${ }^{150}$.

Während der biologische Körper Rudolfs II. allmählich zerfiel, wurde die Herrschaft seines sozialen Körpers durch die Gegenstände, die den Leichnam des Kaisers umgaben, noch betont: Dazu gehörte die goldene Collane mit dem goldenen Widderfell, die der Herrscher kurz vor dem Verschließen des Sarges um den Hals trug. Rudolf II. erhielt den Orden vom Goldenen Vlies am 2. Juni 1585 bei einer Zeremonie im St.-Veits-Dom in Prag aus den Händen Ferdinands von Tirol. Der Onkel des Kaisers traf im Auftrag des Königs Philipp II. in Prag aus Innsbruck ein und vertrat bei der Verleihung der höchsten persönlichen Auszeichnung den spanischen Monarchen ${ }^{151}$. Gemäß den Ordensgrundsätzen sollte die Kette mit dem Goldenen Vlies nach dem Tod seines Besitzers an den spanischen König zurückgegeben werden, um weiter verliehen zu werden ${ }^{152}$. Im Einklang mit dieser Bestimmung wurde die goldene Kette, die einst Rudolf II. gehört hatte, im Jahr 1614 nach Madrid gesandt, wo sie Ulrich Desiderius Pruskowsky von Pruskau in die Hände Philipps III. legte ${ }^{153}$.

Die goldene Kette mit dem daran hängenden Widderfell entfernte man kurz vor dem Verschließen des Sarges und dem Beschlagen des Deckels mit einer Holztafel, zu dem es nach dem Zeugnis des sächsischen Gesandten Melchior Goldasts auf Befehl Adams von Trauttmansdorff unmittelbar nach der Verabschiedung vom Verstorbenen kam. In den darauffolgenden Tagen avancierte sie zum fixen Bestandteil der Trauerde-

147 Tři francouzští kavalíři (wie Anm. 4) 83, 99.

148 Kantorowitz, The King's Two Bodies (wie Anm. 22); Sergio Bertelli, Il corpo del re: sacralità del potere nell'Europa medievale e moderna (Firenze 1990) $22 \mathrm{f}$.

149 NA, SO, CA - Vatikán, Ř́m, Itálie, Kart. 223 (Tomasso Roncaroli an Ranuccio Farnese, Herzog von Parma und Piacenza, Prag, 6. 2. 1612); Lietzmann, Herzog Heinrich Julius (wie Anm. 98) 70.

150 Schlecker, Das Prager Tagebuch (wie Anm. 98) 261 - in freier tschechischer Übersetzung PÁnek, Když císař odchází (wie Anm. 22) 15; Janáček, Rudolf II. a jeho doba (wie Anm. 1) 505. Die fortschreitende Zersetzung des Leichnams hing offensichtlich nicht mit der Einbalsamierung zusammen. Von der guten Arbeit der Barbiere zeugt der gute Erhaltungszustand der Kleidung des Kaisers im Sarg. Die Kleidung, in der er beigesetzt worden war, erhielt sich in einem besseren Zustand als zum Beispiel die Kleidung Maximilians II.; vgl. Bravermanová-Lutovskŕ, Hroby (wie Anm. 127) 242.

151 Václav BŮžEK, Ferdinand von Tirol zwischen Prag und Innsbruck. Der Adel aus den böhmischen Ländern auf dem Weg zu den Höfen der ersten Habsburger (Wien-Köln-Weimar 2009) 283-300.

152 José Romero De Juseu y Lerroux, Marqués De Cárdenas, El Toisón de Oro. Orden dinástica de los duques de Borgoña (Madrid 1960); La insigne Orden del Toisón de Oro, hg. von Alfonso CebalLos-Escalera y Gila (Madrid 1996).

153 Archivo General de Simancas, Estado-Alemania, leg. 2500, fol. 95-109 (Sumario de lo que contienen las cartas de Baltasar de Zúñiga de 16 de marzo y 19 de marzo de 1614). 
korationen von Rudolfs castrum doloris, wo die Kette gemeinsam mit anderen Symbolen (wie dem Schwert) den über den Sarg platzierten Behang zierte ${ }^{154}$.

Im März 1612, während der Leichnam des Kaisers in der Allerheiligenkirche lag, berichteten die ausländischen Gesandten über die Eindrücke, die sie bei der Besichtigung der privaten Gemächer Rudolfs II. erhalten hatten: Der Heilige Stuhl stellte fest, dass der verstorbene Kaiser nicht nur unkluge politische Entscheidungen getroffen hatte, welche die Folge seines krankhaften Geisteszustandes waren, sondern dass Rudolf zudem im katholischen Glauben nicht fest verankert war, weil Giovanni Battista Salvago unter den Kunstwerken Bilder mit Motiven fand, die Nonnen, katholische Geistliche und die römischen Kardinäle generell schmähten. Da diese Kunstwerke in den Augen des päpstlichen Nuntius den katholischen Glauben gefährdeten, forderte er unverzüglich den Wiener Bischof Melchior Khlesl, den engen Vertrauten von König Matthias, auf, er möge für eine Entfernung dieser Bilder aus der Prager Burg sorgen ${ }^{155}$.

In Madrid verbreitete sich die Nachricht vom Ableben Rudolfs II. durch Abschriften in Windeseile innerhalb der Stadt. Zwei Exemplare befinden sich in den Beständen der Jesuitensammlung, die in der zweiten Hälfte des 19. Jahrhunderts in das Archiv der Spanischen königlichen Akademie inkorporiert wurde ${ }^{156}$. In dieser Sammlung findet sich auch ein vertraulicher Auszug eines aus Rom am 28. März 1612 abgeschickten Briefes, dessen Empfänger einer der bedeutenden Vertreter der Provinz des Ordens der Gesellschaft Jesu in Madrid war ${ }^{157}$. Vom nüchternen Bericht aus der Prager Nuntiatur, der ebenso wie andere Zeugnisse durch kultivierte höfische Dissimulation gekennzeichnet war, unterscheidet sich die für die Jesuiten bestimmte Relation durch die ungewöhnliche Offenheit, mit der über die Persönlichkeit Rudolfs und über die Situation am Kaiserhof berichtet wird ${ }^{158}$. Der Verfasser vermittelte das Bild eines Kaisers, der sich zurückzog und, anstatt sich um sein Reich und sein Seelenheil zu kümmern, Hirsche im königlichen Gehege jagte, der Leidenschaft für die Alchemie verfiel und in der Prager Burg ausgefallene und ausgeklügelte Verstecke für seine Juwelen und sein Geld suchte. Dem kritischen Auge des Verfassers entging im Frühling 1612 auch das Benehmen von Matthias nicht, dem er ungeschminkt Habgier vorwarf. Dies sei der eigentliche Hauptgrund, warum sich Matthias so schnell von Wien nach Prag begeben hätte, um nämlich den Schatz Rudolfs - angeblich Schmuck und Geld im Wert von mehreren Millionen Gulden - sicherzustellen ${ }^{159}$.

Die Verherrlichung des unsterblichen sozialen Körpers des Kaisers sollte mit dem Leichenkondukt in Prag ihren Höhepunkt erreichen; über den Zeitpunkt und den Ab-

154 Vocelka, Die politische Propaganda (wie Anm. 3) 327; in freier tschechischer Übersetzung PÁNeK, Když císař odchází (wie Anm. 22) 19.

155 NA, SO, CA - Vatikán, Ř́m, Itálie, Kart. 109 (Giovanni Battista Salvago an Kardinal Scipio Caffarelli-Borghese, Prag, 9.3.1612); Václav BůžEK, Der Heilige Stuhl und die böhmischen Länder während des Pontifikats Pauls V., in: Die Außenbeziehungen der römischen Kurie unter Paul V. Borghese (1605-1621), hg. von Alexander Koller (BDHIR 115, Tübingen 2008) 121-141, hier 135-139.

156 Real Academia de la Historia, Madrid, Colección jesuitas, tomo 105, fol. 245-246 (Relación de la muerte del Emperador); ebd., tomo 88, fol. 331 (Relación de la muerte del Emperador en Praga).

157 Es lässt sich allerdings nicht ausschließen, dass der Brief ursprünglich für eine hochgestellte geistliche oder weltliche Person am spanischen Königshof bestimmt war und in die Jesuitensammlung in Form einer Abschrift gelangte.

158 Real Academia de la Historia, Madrid, Colección jesuitas, tomo 89, fol. 180-181 (por carta de Roma de 28 de marzo de 1612).

159 Ebd. 
lauf herrschten jedoch bei Hof unterschiedliche Meinungen vor. Während Matthias aus persönlichen, politischen und finanziellen Gründen eine bescheidene Trauerfeier wünschte, waren seine Brüder und die Mehrheit der obersten böhmischen Landesbeamten gänzlich anderer Ansicht. Gestützt auf die schriftlichen, bildlichen und mündlichen Zeugnisse von den prunkvollen Feierlichkeiten bei den Begräbnissen von Ferdinand I. und Maximilian II. plädierten sie unter Hinweis auf die dynastische Tradition für eine entsprechend repräsentative Trauerfeierlichkeit ${ }^{160}$, die in der Öffentlichkeit Kontinuität und Ordnung visualisieren sollte ${ }^{161}$. Während die Vorstellungen über ein Begräbnis in Prag in den Frühlingsmonaten des Jahres 1612 noch weit auseinanderklafften, fanden die Exequien für den hingeschiedenen Herrscher bald nach dem Tod Rudolfs in Florenz, Antwerpen, Brüssel und Madrid statt. In der Hauptstadt des Königreichs Böhmen wurde die Trauerfeier für Rudolf II. dagegen erst Anfang Oktober desselben Jahres abgehalten ${ }^{162}$.

Die ausländischen Gesandten, die Hofwürdenträger und die Landesbeamten vermitteln ein gutes Bild von den Krankheiten und von der Persönlichkeit Rudolfs II. In diesen an die west-, süd- und zentraleuropäischen Metropolen verschickten Berichten lassen die Diplomaten eigene Beobachtungen aus den diplomatischen Verhandlungen und von den Audienzen einfließen, aber auch Informationen aus dem Umkreis von Rudolfs Leibärzten und Leibkämmerern. Obwohl sie Rudolfs Gesundheitszustand - meist als Melancholie klassifiziert - bis ins kleinste Detail beschrieben, forschten sie kaum nach den Ursachen seiner Erkrankungen, sondern stellten vor allem Überlegungen zur Handlungsfähigkeit Rudolfs an.

Die Verherrlichung des unsterblichen sozialen Körpers des Kaisers begann mit der Aufbahrung in der Prager Burg und erreichte während der katholischen Exequien in Antwerpen, Brüssel, Florenz, Madrid und in den Reichsstädten einen ersten Höhepunkt. Diese Trauerfeierlichkeiten für Rudolf II. unterschieden sich sowohl zeitlich, als auch im Zeremoniell und durch die symbolisch durchdachte Dramaturgie der Zeremonien deutlich voneinander. Allen war gemeinsam: Rudolf II. wurde im kollektiven Gedächtnis als tugendhafter Herrscher, als christlicher Ritter und als Kämpfer für den katholischen Glauben inszeniert. Obwohl das Bild des sozialen Körpers Rudolfs II. deutlich mit der irdischen Sichtweise bezüglich der kaiserlichen Handlungsfähigkeit zu Lebzeiten kontrastierte, kam die Überhöhung der Gestalt Rudolfs in den nachgelassenen

${ }^{60}$ Géza PÁlffy, Ungarn in der Habsburgermonarchie. Ungarische Herrschaftszeichen an der Wiener Begräbniszeremonie Kaiser Ferdinands I. 1565, in: Wien und seine WienerInnen. Ein historischer Streifzug durch Wien über die Jahrhunderte, hg. von Martin Scheutz-Vlasta Valeš (Wien-Köln-Weimar 2008) 29-46; DERS., Kaiserbegräbnisse in der Habsburgermonarchie - Königskrönungen in Ungarn. Ungarische Herrschaftssymbole in der Herrschaftrepräsentation der Habsburger im 16. Jahrhundert. frühneuzeit-info 19 (2008) 41-66; Rosemarie VocELKa, Die Begräbnisfeierlichkeiten für Kaiser Maximilian II. 1576/77. MIÖG 84 (1976) 105-136; Václav BŮžEK, Die Begräbnisfeierlichkeiten nach dem Tod Ferdinands I. und seiner Söhne. Historie - otázky - problémy 7 (2015) 260-273.

${ }_{161}$ HHStA, FA, Kart. 65; Vocelka, Die politische Propaganda (wie Anm. 3) 324f.; Ders., Rudolf II. und seine Zeit (wie Anm. 1) 214.

162 Ausführlich BŮžEK-MareK, Smrt Rudolfa II. (wie Anm. 20) 48-88. 
Allegorien voll zur Geltung ${ }^{163}$. Rudolf II. wurde gemäß der Tradition seiner mythischen Vorfahren in einem festlich geschmückten Sonnenwagen des kühnen griechischen Gottes Herkules gezeigt, der zum Olymp der göttlichen Ewigkeit auffährt ${ }^{164}$ - der Sonnenwagen wurde vom böhmischen Löwen und dem Reichsadler gezogen. Den Triumph der Ewigkeit des unsterblichen sozialen Körpers Kaiser Rudolfs II. begleiteten Sonnenstrahlen, welche den Willen Gottes symbolisierten.

163 Näher die Allegorie auf den Tod Rudolfs II. unter dem Titel In mirum omen Rodolphi II. imperatoris obitum ante gressum. Vgl. den symbolischen Inhalt des lateinischen Textes im Kupferstich von Johann Matthias Wacker von Wackenfels.

164 Karl Vocelka-Lynne Heller, Die Lebenswelt der Habsburger. Kultur- und Mentalitätsgeschichte einer Familie (Graz-Wien-Köln 1997) 221-223; Guido BrucK, Habsburger als „Herculier“. Jahrbuch der kunsthistorischen Sammlungen in Wien 50 (1953) 191-198.

MIÖG 125 (2017) 